\title{
Surface Solar Radiation in North America: A Comparison of Observations, Reanalyses, Satellite, and Derived Products*
}

\author{
ANDREW G. SLATER \\ National Snow and Ice Data Center, CIRES, University of Colorado Boulder, Boulder, Colorado
}

(Manuscript received 22 May 2015, in final form 8 September 2015)

\begin{abstract}
Observations of daily surface solar or shortwave radiation data from over 4000 stations have been gathered, covering much of the continental United States as well as portions of Alberta and British Columbia, Canada. The quantity of data increases almost linearly from 1998, when only several hundred stations had data. A quality-control procedure utilizing threshold values along with computing the clear-sky radiation envelope for individual stations was implemented to both screen bad data and rescue informative data. Over two-thirds of the observations are seen as acceptable. There are 15 different surface solar radiation products assessed relative to observations, including reanalyses [Twentieth-Century Reanalysis (20CR), CFS Reanalysis and Reforecast (CFSRR), ERA-Interim, Japanese 55-year Reanalysis Project (JRA-55), MERRA, NARR, and NCEP-NCAR Reanalysis 1 (NCEP-1)], derived products [observations from the CRU and NCEP-1 (CRUNCEP); Daily Surface Weather and Climatological Summaries (Daymet); Global Land Data Assimilation System, version 1 (GLDAS-1); Global Soil Wetness Project Phase 3 (GSWP3); Multiscale Synthesis and Terrestrial Model Intercomparison Project (MsTMIP); and phase 2 of the North American Land Data Assimilation System (NLDAS-2)], and two satellite products (CERES and GOES). All except the CERES product have daily or finer temporal resolution. The RMSE of spatial biases is greater than $18 \mathrm{~W} \mathrm{~m}^{-2}$ for 13 of the 15 products over the summer season (June-August). None of the daily resolution products fulfill all three desirable criteria of low $(<5 \%)$ annual or seasonal bias, high correlation with observed cloudiness, and correct distribution of clear-sky radiation. Some products display vestiges of underlying algorithm issues [e.g., from the Mountain Microclimate Simulation Model, version 4.3 (MTCLIM 4.3)] or bias-correction methods. A new bias-correction method is introduced that preserves clear-sky radiation values and better replicates cloudiness statistics. The current quantity of data over the continental United States suggests that a solar radiation product based on, or enhanced with, observations is feasible.
\end{abstract}

\section{Introduction}

Incoming solar, or shortwave, radiation is an integral part of the surface energy balance and can often be the largest energy source at the earth's surface. The amount of energy available at the surface will play a central role in determining the partitioning among sensible, latent, and conductive energy fluxes at the surface. Similarly, the hydrologic budget is heavily influenced by solar

\footnotetext{
* Supplemental information related to this paper is available at the Journals Online website: http://dx.doi.org/10.1175/JHM-D-150087.s1.

Corresponding author address: Andrew G. Slater, National Snow and Ice Data Center, CIRES, University of Colorado Boulder, Campus Box 449, Boulder, CO 80309-0449.

E-mail: aslater@colorado.edu
}

radiation as evaporation is governed by net radiation. Furthermore, biological activity such as photosynthesis, and in turn carbon cycling, is dependent on the amount and type (whether direct or diffuse) of solar radiation (Monteith 1972). Knowledge of surface radiation can also be of use for evaluation and development of atmospheric radiative transfer models (Wild et al. 2014), which in turn can improve climate outlooks and weather forecasting. The use of solar power (e.g., via photovoltaic cells) is increasing and is projected to keep doing so over the next decade (Reichelstein and Yorston 2013), so a better understanding of the spatial and temporal distribution of the surface flux can be of use for planning.

The potential benefits of more physically based hydrology and land surface models are becoming recognized, but part of their limitation lies in the need for more explicit input (forcing) data, which typically include surface global solar radiation. Operational hydrologic 
forecasting systems, such as those of the U.S. National Weather Service, still rely on simplified conceptual temperature index models (Anderson 1973, 2006) as a primary tool, in part because of a lack of appropriate forcing data. The required forcing variables are observed at different spatial densities, both at the national (United States) and global scale; for example, observations of temperature and precipitation are much more common than those of radiation.

Because of the need for spatially and temporally complete fields of forcing data, continental- or globalscale efforts of modeling mass and energy fluxes at the earth's surface usually derive solar radiation from reanalysis projects, often applying indirect observational (Sheffield et al. 2006) or satellite-derived (Cosgrove et al. 2003; Ngo-Duc et al. 2005) bias corrections. Reanalysis datasets are continually improving as more observational data become available along with advances in modeling and data assimilation systems; spatial and temporal resolution of these systems has increased such that hourly surface meteorology is now becoming available at $0.3^{\circ}$ or finer resolution (Saha et al. 2010, 2014). Alternatively, empirical estimation approaches have been used for ecologic and hydrologic modeling studies (Thornton and Running 1999; Bohn et al. 2013; Livneh et al. 2013).

However, gauging the uncertainty of solar radiation values at the continental scale via in situ data has been challenging, perhaps because of a lack of extensive reliable observations. As examples, the Baseline Surface Radiation Network (BSRN; http://www.bsrn.awi.de/) has 58 well-maintained stations in contrasting climate zones across the world that measure numerous radiation variables, and SURFRAD keeps seven stations in the United States and contains a similar quality of data. The Global Energy Balance Archive (GEBA; Gilgen and Ohmura 1999) stores monthly means of solar radiation spanning 1922-96 and has up to 1405 stations, many of which are in Europe. These high-quality networks, along with others, have often been used for evaluation purposes (section 2f), but provide limited spatial coverage and on their own are insufficient to provide the sort of spatially and temporally complete product required for model simulations and development or climatological analysis.

This study presents extensive observations of surface downward global solar radiation $S_{\text {surf }}$ and compares this collection with existing products available from atmospheric reanalyses, derived methods, or satellite data. The study area is North America, predominantly regions in the contiguous United States (CONUS) and portions of Alberta and British Columbia, Canada. The data used in this study are presented in section 2 and results of comparisons are given in section 3, with discussion in section 4 and conclusions in section 5 .

\section{Data}

\section{a. Station data}

Observed data from numerous station networks were gathered for this study. It is particularly important to recognize all the networks and data sources as shown in Table 1 for operation of the observation stations and for placing data on the Internet. Such efforts are commended. Data from both state- and national-level networks were used; for example, the RAWS and Natural Resources Conservation Service (NRCS) SCAN stations span many states. A number of networks are maintained for the purpose of monitoring agricultural potential. The combined coverage of many data sources makes a broader-scale comparison of solar radiation products possible. There are over 4000 stations with at least 180 days of raw $S_{\text {surf }}$ data at various times between 1990 and 2013 (Fig. 1); the number of stations increased near linearly from 1998 . The 218 stations north of $56^{\circ} \mathrm{N}$ (in Alaska) are excluded from this analysis and will be considered in a further study, as well as those in Hawaii.

All data except the North Carolina network were obtained directly from websites (as given in Table 1) in a mix of 5-min, 15-min, 30-min, hourly, or daily time steps, though most are daily. Data files involved over 35 different formats with varying numbers of associated variables such as air temperature, precipitation, humidity measurements, and wind speeds. Solar radiation data were stored in a variety of units $\left\{\right.$ with $\mathrm{W} \mathrm{m}^{-2}, \mathrm{Lyh}^{-1}$ [where 1 Langley (Ly) $=41840 \mathrm{~J} \mathrm{~m}^{-2}$ ], $\mathrm{kJ} \mathrm{h}^{-1}$, and $\mathrm{MJ}$ day $^{-1}$ being most common $\}$. Date and time stamps in the data files similarly were presented in a multitude of formats, most in LT, though some in UTC. Daily data were calculated based on local time as this was how most were given. Station metadata also varied in completeness, with some networks only offering a latitude and longitude while others gave elevation, county, time zone, date of station activation or decommission, and instrument listing along with photos of the station.

There are many data sources that could contribute further information. For example, data from numerous research projects have not been used largely because the ratio of obtained data relative to the time and effort required to make data readable is prohibitive. Effort toward data archive standardization of basic meteorological variables may improve this situation.

If all station instruments were operating properly, measurement error should still be considered. Gueymard and Myers (2009) give a comparison of monthly average 
TABLE 1. Observation networks with solar radiation data

\begin{tabular}{|c|c|c|c|}
\hline Code & Website URL & Location & Name \\
\hline ACIS & http://agriculture.alberta.ca/acis/ & Alberta, Canada & $\begin{array}{l}\text { Alberta AgroClimatic In- } \\
\text { formation Service }\end{array}$ \\
\hline AGRIMET-GP & http://www.usbr.gov/gp/agrimet/ & U.S. Great Plains & $\begin{array}{l}\text { U.S. Bureau of Reclamation, } \\
\text { Great Plains }\end{array}$ \\
\hline AGRIMET-PN & http://www.usbr.gov/pn/agrimet/ & Pacific Northwest & $\begin{array}{l}\text { U.S. Bureau of Reclamation, } \\
\text { Pacific Northwest }\end{array}$ \\
\hline AWIS & http://www.awis.com/mesonet/ & Alabama & Auburn University Mesonet \\
\hline AZMET & http://ag.arizona.edu/azmet/az-docs.htm & Arizona & $\begin{array}{l}\text { The Arizona Meteorological } \\
\text { Network }\end{array}$ \\
\hline CIMIS & http://wwwcimis.water.ca.gov/cimis/welcome.jsp & California & $\begin{array}{l}\text { California Irrigation Manage- } \\
\text { ment Information System }\end{array}$ \\
\hline CoAgMet & http://ccc.atmos.colostate.edu/ coagmet/ & Colorado & $\begin{array}{l}\text { Colorado Agricultural Mete- } \\
\text { orological Network }\end{array}$ \\
\hline DEOS & http://www.deos.udel.edu/ & Delaware & $\begin{array}{l}\text { Delaware Environmental } \\
\text { Observing System }\end{array}$ \\
\hline FAWN & http://fawn.ifas.ufl.edu/ & Florida & $\begin{array}{l}\text { Florida Automated Weather } \\
\text { Network }\end{array}$ \\
\hline WARM & http://www.isws.illinois.edu/warm/icnsitemap.asp & Illinois & $\begin{array}{l}\text { Water and Atmospheric Re- } \\
\text { sources Monitoring } \\
\text { Program }\end{array}$ \\
\hline IEM & http://mesonet.agron.iastate.edu/agclimate/info.phtml & Iowa & Iowa Environmental Mesonet \\
\hline ICLIMATE & http://iclimate.org/index.asp & Indiana & Indiana State Climate Office \\
\hline $\mathrm{KCC}$ & http://wdl.agron.ksu.edu/ & Kansas & $\begin{array}{l}\text { Kansas State University } \\
\text { Weather Data Library }\end{array}$ \\
\hline KYMESO & http://kymesonet.org/index.html & Kentucky & Kentucky Mesonet \\
\hline LSU & http://weather.lsuagcenter.com/reports.aspx & Louisiana & $\begin{array}{l}\text { Louisiana State University } \\
\text { AgCenter }\end{array}$ \\
\hline MAWN & http://www.agweather.geo.msu.edu/mawn/ & Michigan & $\begin{array}{l}\text { Michigan Automated } \\
\text { Weather Network }\end{array}$ \\
\hline MISSOURI & http://agebb.missouri.edu/weather/stations/ & Missouri & $\begin{array}{l}\text { Commercial Agriculture Pro- } \\
\text { gram, Missouri University }\end{array}$ \\
\hline NDAWN & http://ndawn.ndsu.nodak.edu/index.html & North Dakota & $\begin{array}{l}\text { North Dakota Agriculture } \\
\text { Weather Network }\end{array}$ \\
\hline NC ECONet & http://www.nc-climate.ncsu.edu/ & North Carolina & North Carolina ECONet \\
\hline NJWXNET & http://climate.rutgers.edu/njwxnet/ & New Jersey & $\begin{array}{l}\text { NJ Climate and Weather } \\
\text { Mesonet }\end{array}$ \\
\hline SCAN & http://www.wcc.nrcs.usda.gov/scan/ & United States & $\begin{array}{l}\text { Soil Climate Analysis } \\
\text { Network }\end{array}$ \\
\hline SNOTEL & http://www.wcc.nrcs.usda.gov/snow/ & Western United States & Snowpack Telemetry \\
\hline OARDC & http://www.oardc.ohio-state.edu/newweather/ & Ohio & $\begin{array}{l}\text { Ohio Agricultural Research } \\
\text { and Development Center }\end{array}$ \\
\hline OK MESONET & http://www.mesonet.org/index.php & Oklahoma & Oklahoma Mesonet \\
\hline RAWS & http://raws.fam.nwcg.gov & United States & $\begin{array}{l}\text { Remote Automatic Weather } \\
\text { Stations }\end{array}$ \\
\hline SDAWDN & http://climate.sdstate.edu/climate_site/ag_data.htm & South Dakota & $\begin{array}{l}\text { South Dakota Automatic } \\
\text { Weather Data Network }\end{array}$ \\
\hline WTXMESO & http://www.mesonet.ttu.edu/ & Texas & West Texas Mesonet \\
\hline TXETN & http://texaset.tamu.edu/ & Texas & $\begin{array}{l}\text { Texas A\&M Texas ET } \\
\text { Network }\end{array}$ \\
\hline CHILI & http://chiliweb.southalabama.edu/archived_data.php & Alabama & $\begin{array}{l}\text { Center for Hurricane In- } \\
\text { tensity and Landfall } \\
\text { Investigation }\end{array}$ \\
\hline NICE & http://nicenet.dri.edu/ & Nevada & $\begin{array}{l}\text { Nevada Integrated Climate } \\
\text { and Evapotranspiration } \\
\text { Network }\end{array}$ \\
\hline CEMP & http://www.cemp.dri.edu/ & Nevada & $\begin{array}{l}\text { Community Environmental } \\
\text { Monitoring Program }\end{array}$ \\
\hline VANI & http://www.islandweather.ca/ & Vancouver Island, Canada & $\begin{array}{l}\text { School-Based Weather Sta- } \\
\text { tion Network }\end{array}$ \\
\hline
\end{tabular}




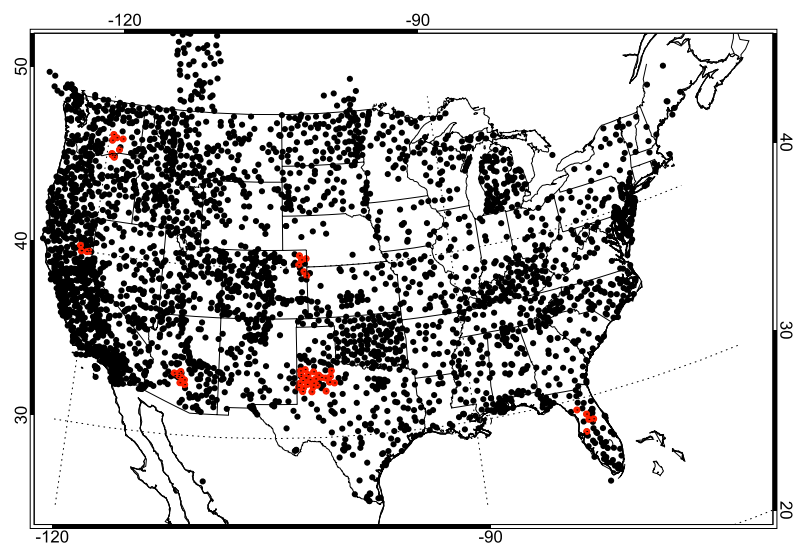

FIG. 1. Location of stations used in this study. Red dots represent the stations used in the regional analysis [section $3 b(2)]$.

global radiation among a range of 12 common commercial pyranometers, both thermopile and silicon-based instruments. Over the whole year, the mean error range was within $\pm 2 \%$ of the reference instruments. However, there was a seasonal cycle within the errors, with winter monthly means showing the largest error (up to $-8 \%$ ) because of the lower zenith angles. Diffuse radiation conditions tended to produce larger errors. Similarly, Stoffel et al. (2000) found errors on the order of $+2.5 \%$ and down to $-10 \%$ in comparison to reference instruments. Cronin and McPhaden (1997) indicate that calibration accuracy of $2 \%$ was available under laboratory conditions for their pyranometers.

\section{b. Data $Q C$}

The disparate data sources in Table 1 contain a wide variety of station maintenance and data curation. Daily mean global solar radiation at the surface is the variable used for this study as it is the most common time step available from all the data sources. This section first outlines some quality-control (QC) methods that have been reported in the literature and then describes the procedures used in the current work. The QC procedure for daily data in this work is designed to be independent of other data sources (as they are not always available) and its primary objective is to be able to identify erroneous data. A further objective is to determine what data may be "rescued" after being flagged as questionable. For the current study, identifying erroneous data is a higher priority than compiling a temporally complete dataset; hence, blocks of data that may contain some good values are removed in preference to screening individual days.

\section{1) QC IN PRIOR STUDIES}

Various methods for QC are in the literature, though many are for hourly data. These use a clearness index,

$$
I_{\text {clear }}=\frac{S_{\text {surf }}}{S_{\text {clear_sky }}},
$$

where $S_{\text {clear_sky }}$ is clear-sky (i.e., cloudless) radiation at the surface. Younes et al. (2005) review a number of rigorous methods for solar radiation QC; however, most are based on the use of $I_{\text {clear }}$ relative to diffuse radiation and thus are not applicable to the situation where data comprise only daily values of global radiation. Journee and Bertrand (2011) describe a QC procedure for subhourly data, though they have the advantage of having direct, diffuse, and reflected radiation values. They apply a series of threshold tests: subhourly $S_{\text {surf }}$ needs to be less than the top-of-atmosphere radiation $S_{\text {toa }}$ and within $110 \%$ of $S_{\text {clear_sky }}$, while daily mean values need to be greater than $3 \%$ of $S_{\text {toa. A series of }}$ plausible envelopes of data are also developed, based on the ratio of $S_{\text {surf }}$ to $S_{\text {toa }}$ relative to the ratio of direct beam or diffuse radiation to $S_{\text {toa }}$, though such a method cannot be applied to the problem at hand. Contamination of sensors, for example, by snow, was screened out if reflected radiation was greater than incoming.

Shi et al. (2008) document a three-step QC procedure with the goal of identifying those data that are physically unreasonable. For the first test, an upper limit of global radiation data is determined as $S_{\text {clear_sky }}$, while the lower limit was set to $3 \% S_{\text {clear_sky }}$. The second test applied by Shi et al. (2008) required additional measurements such as sunshine duration, while for the third test, a 15-yr time series was used to identify erroneous data from valid outlier cases.

\section{2) QC APPLIED IN THIS STUDY}

Where possible, some of the above QC concepts have been applied to the data in this study, for example, threshold values. However, the highly variable length of observational record at each station along with the use of daily $S_{\text {surf }}$ data without components like reflected or diffuse data meant that alternative methods needed to be developed. The procedure for QC of observations collected for this project follows a number of steps:

1) basic screening of daily and subdaily $S_{\text {surf }}$ and computation of daily means;

2) compute daily clear-sky radiation values [i.e., $S_{\text {clear_sky; }}$; section $\left.2 \mathrm{~b}(3)\right]$;

3) fit a clear-sky ratio (CSR), if possible to do so, based on tests described in section $2 b(4)$;

4) check for excessive high values or continuously low values relative to the CSR;

5) of the remaining data, choose the acceptable CSR range for a given application; 
6) rescale data according to the CSR (e.g., to filter for an erroneous trend); and

7) filter the remaining data with thresholds and unlikely occurrences.

The QC started with an initial screening of subdaily data in which distinctly bad data were removed, for example, values below -5 or above $1400 \mathrm{~W} \mathrm{~m}^{-2}$. Seemingly impossible negative or excessively high values can be registered because of calibration issues that may be corrected later. A full set of data for sunlight-hours per day (with an additional hour at the start and end of the solar day) was required when computing a daily mean from subdaily data. Many stations also underwent manual and visual screening to remove erratic data. All further tests were applied to daily data.

\section{3) Clear-SKy RAdiation Via THE BiRd AND HULSTROM MODEL}

Clear-sky global radiation was determined via the Bird and Hulstrom (1981) model. The model uses latitude, longitude, and elevation (as for $S_{\text {toa }}$ ) for solar geometry calculations, but it also requires knowledge of atmospheric water content, aerosol optical depth (AOD), and surface albedo to compute attenuation and scattering of radiation in the atmosphere, thus giving $S_{\text {clear_sky. Atmospheric water content was derived from }}$ the Climate Forecast System Reanalysis and Reforecast (CFSRR) because of its high spatial resolution and in North America there is a relatively high density of radiosondes for assimilation. AOD was derived from the MISR sensor (MISR_AM1_CGAS F15_0031, MIL3MAE; https://eosweb.larc.nasa.gov/project/misr/ cgas_table). The MISR product is a monthly optical depth with data from February 2000 through present. Missing values occur in this dataset; thus, each month missing MISR values are first filled on a spatial basis via Cressman (1959) weighting of neighboring grid cells within $90 \mathrm{~km}$. From March 2003 onward, over $90 \%$ of the CONUS was covered with data after spatial filling. For times and locations that could not be filled this way, a climatological value for the particular location and month was used. Daily and subdaily values of AOD were obtained via a spline interpolation of the monthly values; obviously, this does not capture day-to-day changes. Surface albedo was derived from the MODIS MOD43A3 product (https://lpdaac.usgs.gov/dataset_discovery/modis/ modis_products_table/mcd43a3), which is at a pixel resolution of $500 \mathrm{~m}$ and available from February 2000 through present (Schaaf et al. 2002). Albedo is available every 8 days using 16 days' worth of data (which is the nadir repeat cycle of the polar-orbiting EOS satellites, Terra and Aqua) and is interpolated to a daily value. For periods when data were not available, climatological values developed over the entire record were used. The $S_{\text {clear_sky }}$ results are not particularly sensitive (on the order of a couple of percent) to AOD or albedo when perturbed within their expected range. The robustness of $S_{\text {clear_sky }}$ results is demonstrated below when compared to observed values [section $2 \mathrm{~b}(4)$ ] and reanalyses (section $3 \mathrm{a}$ ).

\section{4) Computing the CSR}

Pyranometers can suffer from poor calibration or poor maintenance. For example, dirt accumulation on the sensor can result in lower-than-true readings (Foltz et al. 2013), or tilting of the radiometer in the direction of the sun or excess reflection may give measured values above $S_{\text {clear_sky. With such data contamination issues in }}$ mind, for a given station over a period of time such as several months, the CSR is computed as

$$
\operatorname{CSR}=\frac{E_{\text {clear_sky }}}{S_{\text {clear_sky }}},
$$

where $E_{\text {clear_sky }}$ is an upper-bound envelope of measured values on days we expect to have had a clear sky. The CSR is computed from an envelope of values and should not be confused with $I_{\text {clear }}$, which can be calculated daily (or hourly).

This $E_{\text {clear_sky }}$ envelope is found as follows. For a given period of data for a particular station, a histogram of daily $I_{\text {clear }}$ values was computed using bin widths of 0.04 . The bracketing values of the bins were iteratively tested for obtaining greatest data discrimination (e.g., whether a bin was, say, 0.95-0.98, as compared to 0.960.99 ); if more than $10 \%$ of the data had an $I_{\text {clear }}$ values above 0.95 , only these data were used in the computation. Greater discrimination refers to a single bin containing a greater portion of the available data. The bin with the largest frequency was chosen as containing the observed clear-sky days, and the CSR is then taken as the mean value of $I_{\text {clear }}$ within that bin. An assumption of the method is that the most frequently occurring upper-bound envelope of $I_{\text {clear }}$ occurs when the sky is clear.

To be accepted as a valid CSR, several criteria had to be satisfied: 1) at least $10 \%$ of considered data had to be within the bin chosen to be the clear-sky case; 2) the clear-sky bin has to have at least $20 \%$ more data than the next most-populated bin, and should this not be the case, $E_{\text {clear_sky }}$ is ambiguous and is not assigned; and 3) if $I_{\text {clear }}$ is 0.5 or less for an extended period of interest, such as a month or more, all data for that period are marked as bad.

A CSR value is computed for each 12 -month period, starting at each month of the year, as well as for just 
the warm season (April-September) and cold season (October-March). Such a piecewise approach is used to account for data gaps (e.g., from initial screening), and instruments may be periodically serviced or may drift with time. If $E_{\text {clear_sky }}$ values had been computed for a given month and location, the closest value to a CSR of 1.0 is selected; remembering that all CSR values are calculated using available data and had to pass several tests for plausibility.

The aim of using a CSR is to both eliminate bad data that under- or overestimate solar radiation as well as to potentially "rescue" as much observed data as possible by rescaling the raw values by their CSR, though this includes an assumption that the error can be equally rescaled under clear and cloudy conditions, which is why the use of CSR rescaling is limited to the range of 0.951.05 in this study. Even with problems such as instrument drift or contamination, the larger variability caused by clouds is still recorded.

Additional checks are made after rescaling raw data by the CSR. First, if over a continually moving 40-day window there exist at least 30 measurements where the mean $S_{\text {clear_sky }}$ value is above $40 \mathrm{~W} \mathrm{~m}^{-2}$ and the maximum $I_{\text {clear }}$ is 0.65 , then all data in the window are marked as bad. Using the same window, if five measurements exceed an $I_{\text {clear }}$ of 1.15 , all data are marked as bad. If measured radiation was less than $3 \%$ of $S_{\text {clear_sky }}$ and daily $S_{\text {clear_sky }}$ was above $50 \mathrm{~W} \mathrm{~m}^{-2}$, the data were considered bad. A more lax $6 \%$ was allowed for lower $S_{\text {clear_sky }}$ values. Data above an $I_{\text {clear }}$ of 1.05 were also removed. The constants used in the QC procedure are gained from visual inspection and testing on a wide variety of station data.

The concept of $E_{\text {clear_sky }}$ is best demonstrated in Fig. 2, where it is shown with a red line, sitting atop the raw observations. The station at Dale Bitner, Idaho, displays a slight downward trend in the measurements that was captured by the CSR. Caputa, South Dakota, shows good-quality data until late summer 2012. Data during autumn 2012 could not obtain a CSR fit and thus were rejected, while the data in 2013 exceeded $S_{\text {clear_sky }}$ but could be rescued or rejected depending on CSR threshold (in this case, CSR exceeds 1.10). Standard threshold tests and variance checks would not necessarily catch the trend at Dale Bitner as all values are quite reasonable. Such tests would reject a portion of the Caputa data that exceeds $S_{\text {clear_sky, }}$, but remaining data could be erroneously accepted. Figures $2 \mathrm{~b}$ and $2 \mathrm{~d}$ show the result when the raw data have been rescaled by the CSR.

A histogram of computed CSR values for all data points that have passed all the above tests is shown in Fig. 3a. It demonstrates that the vast majority of values
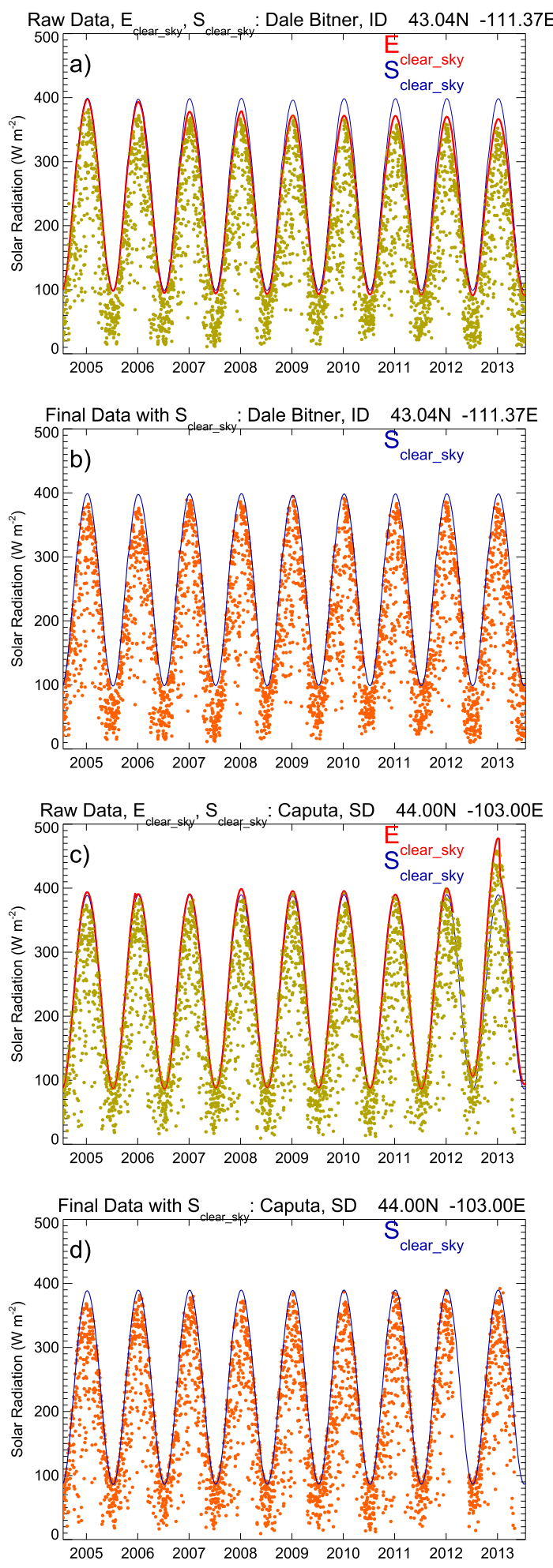

FIG. 2. Examples of (a) raw data (yellow dots) with the envelope of clear-sky days (i.e., $E_{\text {clear_sky; }}$ red line) and expected clear-sky radiation (i.e., $S_{\text {clear_sky }}$; blue line) and (b) final data (orange dots) with the envelope of expected clear-sky radiation (i.e., $S_{\text {clear_sky; }}$; blue line) for Dale Bitner, Idaho. (c),(d) As in (a),(b), but for Caputa, South Dakota. 

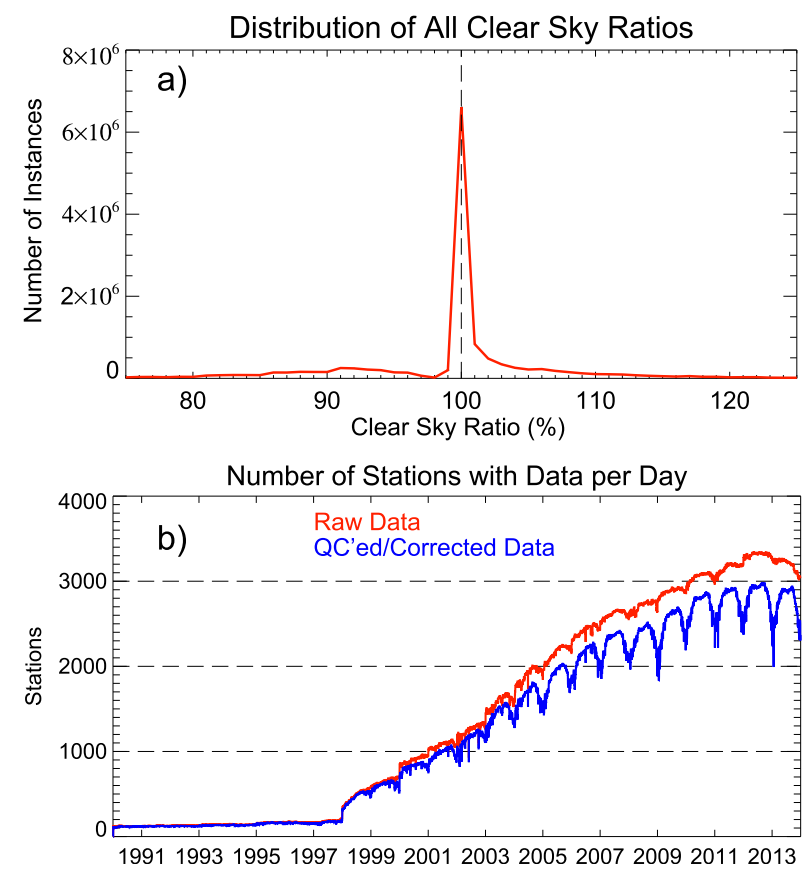

FIG. 3. (a) The histogram of calculated CSRs over the span of all data, expressed as a percentage. Note the large peak at $100 \%$. (b) The quantity of raw and quality-controlled data over the period of record. The scalloped pattern of quality-controlled data is likely due to screening of snow contamination. Over 4000 stations are in the record, but not all were continuously active.

are between 0.99 and 1.01, which would suggest that the system is correctly finding the clear-sky cases and that $S_{\text {clear_sky }}$ values used in the analysis are very close to observed. The maximum number of potentially valid stations at any one time reaches almost $3000(0.75>$ CSR $>1.25$; Fig. 3 b) and about $74 \%$ of the original raw data have a CSR between 0.95 and 1.05. The scalloped shape of the quality-controlled data quantity shows a drop during winter and may suggest screening of snow contamination. However, the lack of fully accounting for intermittent snowfall on sensors remains a weakness, so caution is urged for snowy cases. Last, it is acknowledged that portions of erroneous data have no doubt failed to be identified and that additional QC tests could be added in the future. The time and effort required for QC has led some prior studies to simply use raw station data (e.g., Zhao et al. 2006) when investigating sensitivity of primary productivity algorithms, and in other instances data have been used though biases or step functions are identified (Jepsen et al. 2012). However, large amounts of the final data underwent visual screening and the total volume of data, along with the spatial coherence in values, likely make for robust results. As noted above, to remain conservative, data used for comparative purposes in this study have been limited to CSRs between 0.95 and 1.05 .

\section{c. Reanalysis data}

The reanalysis datasets evaluated in this study are listed in Table 2 along with their respective specifications, references, and websites. Solar radiation is a forecast field in reanalysis systems, meaning that there are no direct measurements of solar radiation assimilated. Seven different reanalyses are used in this study. Four are the "new generation" of global reanalyses that all run at subdegree spatial resolution: NASA's Modern-Era Retrospective Analysis for Research and Applications (MERRA; Rienecker et al. 2011), NOAA's CFSRR (Saha et al. 2010), the ECMWF interim reanalysis (ERA-Interim, hereafter ERAI; Dee et al. 2011), and most recently the Japanese 55-year Reanalysis Project (JRA-55; Kobayashi et al. 2015). Slightly older reanalyses included here are the original NCEP-NCAR Reanalysis 1 (hereafter NCEP-1; Kalnay et al. 1996) and the North American Regional Reanalysis (NARR; Mesinger et al. 2006). The reanalyses mentioned so far assimilate information about profiles of atmospheric temperature and humidity from satellite radiances, aircraft measurement, and radiosondes, which in turn impact the radiative transfer calculations that provide the surface flux of solar radiation. In contrast, the Twentieth-Century Reanalysis (20CR; Compo et al. 2011), which spans the greatest time period, assimilates only surface atmospheric pressure and uses an ensemble assimilation technique; the flux values used here are the mean of the ensemble. Several of these products are used for compiling subsequent datasets.

\section{d. Derived data products}

Derived products are usually developed for the purpose of forcing land surface, hydrology, ecology, and biome models, or for gridded analysis of surface meteorology. Typically, they are combinations of various items such as reanalyses, observed data, and algorithms and are often subject to some form of bias correction.

The Daily Surface Weather and Climatological Summaries (Daymet) product is calculated using the Mountain Microclimate Simulation Model, version 4.3 (MTCLIM 4.3; Thornton and Running 1999), with daily minimum and maximum air temperature and daily precipitation. Calculated for the CONUS, data were supplied from the Cooperative Observer network across the country and the higher-elevation NRCS SNOTEL network in the western states. On the order of 32000 41000 stations were used in the United States within a given year. Input data were interpolated to produce a product at $1-\mathrm{km}$ resolution.

The CRU-NCEP data, developed and maintained by N. Viovy and colleagues [Laboratoire des Sciences du 
TABLE 2. Solar radiation products available across the CONUS.

\begin{tabular}{|c|c|c|c|c|}
\hline Dataset & Spatial resolution & $\begin{array}{l}\text { Temporal } \\
\text { resolution }\end{array}$ & Period used & Reference and website \\
\hline \multicolumn{5}{|l|}{ Reanalyses } \\
\hline CFSRR & $0.32^{\circ}$ & 1 hourly & $1990-2010$ & Saha et al. (2010); http://cfs.ncep.noaa.gov/cfsr/ \\
\hline ERAI & $0.75^{\circ}$ & 3 hourly & $1990-2013$ & $\begin{array}{l}\text { Dee et al. (2011); http://apps.ecmwf.int/datasets/data/interim-full- } \\
\text { daily/ }\end{array}$ \\
\hline JRA-55 & $0.50^{\circ}$ & 3 hourly & 1990-2013 & Ebita et al. (2011); http://jra.kishou.go.jp/JRA-55/index_en.html \\
\hline MERRA & $0.5^{\circ} \times 0.66^{\circ}$ & 1 hourly & 1990-2013 & Rienecker et al. (2011); http://gmao.gsfc.nasa.gov/merra/ \\
\hline NARR & $32 \mathrm{~km}$ & 3 hourly & $1990-2013$ & $\begin{array}{l}\text { Mesinger et al. (2006); http://www.esrl.noaa.gov/psd/data/gridded/ } \\
\text { data.narr.html }\end{array}$ \\
\hline NCEP-1 & $2.5^{\circ}$ & 6 hourly & 1990-2013 & $\begin{array}{l}\text { Kalnay et al. (1996); http://www.esrl.noaa.gov/psd/data/gridded/ } \\
\text { data.ncep.reanalysis.html }\end{array}$ \\
\hline $20 \mathrm{CR}$ & $2.0^{\circ}$ & 3 hourly & 1990-2013 & $\begin{array}{l}\text { Compo et al. (2011); http://www.esrl.noaa.gov/psd/data/20thC_ } \\
\text { Rean/ }\end{array}$ \\
\hline \multicolumn{5}{|l|}{ Derived products } \\
\hline Daymet & $1 \mathrm{~km}$ & Daily & 1990-2013 & Thornton and Running (1999); http://daymet.ornl.gov/ \\
\hline CRU-NCEP & $0.50^{\circ}$ & 6 hourly & 1990-2012 & Wei et al. (2014); http://dods.extra.cea.fr/data/p529viov/cruncep/ \\
\hline MsTMIP & $0.25^{\circ}$ & 3 hourly & $1990-2010$ & Wei et al. (2014); http://nacp.ornl.gov/MsTMIP.shtml \\
\hline NLDAS-2 & $0.125^{\circ}$ & 1 hourly & 1990-2013 & $\begin{array}{l}\text { Cosgrove et al. (2003); http://ldas.gsfc.nasa.gov/nldas/NLDAS2forcing. } \\
\text { php }\end{array}$ \\
\hline GSWP3 & $0.5^{\circ}$ & 3 hourly & 1990-2010 & $\begin{array}{l}\text { Yoshimura and Kanamitsu (2013); http://hydro.iis.u-tokyo.ac.jp/ } \\
\text { GSWP3/ }\end{array}$ \\
\hline GLDAS-1 & 1.0 & 3 hourly & 1990-2013 & Rodell et al. (2004); http://ldas.gsfc.nasa.gov/gldas/ \\
\hline \multicolumn{5}{|c|}{ Satellite products } \\
\hline GOES & $0.5^{\circ}$ & Daily & $1996-2010$ & Pinker and Laszlo (1992); http://www.atmos.umd.edu/ srb/gcip/ \\
\hline CERES & $1.0^{\circ}$ & Monthly & $2000-13$ & $\begin{array}{l}\text { Kato et al. (2013); http://ceres.larc.nasa.gov/products.php? } \\
\text { product=EBAF-Surface }\end{array}$ \\
\hline
\end{tabular}

Climat et de l'Environnement (LSCE), France], are a blend of NCEP-1 and observations maintained by the Climatic Research Unit (CRU; University of East Anglia). A description accompanies the data and is given in Wei et al. (2014). Using observed cloud cover from CRU, date, and latitude, the empirical method of Berliand (1960) is used in the generation of solar radiation. The noted high bias of NCEP-1 radiation is thus reduced. This CRU-NCEP dataset has been used for many modeling studies, for example, the Trends in Net Land-Atmosphere Carbon Exchange (TRENDY) project (Piao et al. 2013).

In an earlier dataset based on CRU and NCEP-1 (Ngo-Duc et al. 2005), NCEP-1 solar radiation data had been bias corrected on a monthly time scale using the Surface Radiation Budget (SRB; http://gewex-srb.larc. nasa.gov; Darnell et al. 1988) estimates of surface solar radiation, which spanned the period 1983-95. A single coefficient was computed for each month of the year and is held constant over the period of the dataset. These earlier data are not used in the current study but are mentioned to avoid confusion.

The Multiscale Synthesis and Terrestrial Model Intercomparison Project (MsTMIP) North American (Huntzinger et al. 2013) solar data are documented by Wei et al. (2014). MTCLIM 4.3 was used to obtain daily solar radiation values, driven by NARR daily maximum and minimum temperatures as well as bias-corrected precipitation. The calculated daily values were then temporally distributed by using NARR 3-hourly solar data as a scaling template.

Phase 2 of the North American Land Data Assimilation System (NLDAS-2) has produced a model forcing dataset from 1979 through present at a $1 / 8^{\circ}$ resolution over the CONUS. The NLDAS- 2 solar radiation data use NARR values interpolated to the finer spatial grid and temporal resolution, then used a product from Geostationary Operational Environmental Satellite-8 (GOES-8) for adjustment, with details given in Cosgrove et al. (2003). Using data spanning 1996-2000, for each month, the mean ratio of GOES-8 to interpolated NARR data was computed for each hour of the day (giving 12month $\times$ 24-h ratios). All interpolated NARR solar values are then rescaled by their respective ratios for each month and hour.

The very recent Global Soil Wetness Project Phase 3 (GSWP3) radiation dataset is based on 20CR and applies a monthly bias correction based on satellite retrievals.

The Global Land Data Assimilation System, version 1 (GLDAS-1), applies a variety of sources for its solar radiation. According to the available documentation, the data are a combination of various sources: 1979-93 
are bias-corrected ECMWF reanalysis data [using the method of Berg et al. (2003)] and 1994-99 are similarly bias-corrected NCEP-1 data. The dataset used for bias correction was the Langley 8-yr short- and longwave SRB (Gupta et al. 1999). For 2000, analysis fields from NOAA's Global Data Assimilation System were used, then from 2001 through present, radiation is from the Agricultural Meteorology Modeling System (AGRMET) algorithm of the Air Force Weather Agency (AFWA; see documentation at http://disc.sci.gsfc.nasa.gov/ hydrology/documentation). AGRMET is based on the three-level radiative transfer model of Shapiro (1987) and uses near-real-time cloud information from DMSP and NOAA satellites. AGRMET's native resolution since 2002 is $24 \mathrm{~km}$. Note that GLDAS, version 2 (GLDAS-2), uses the Sheffield et al. (2006) dataset but is not updated to the present and hence is not used in this study.

\section{e. Satellite data}

The Clouds and the Earth's Radiant Energy System (CERES) Energy Balanced and Filled (EBAF) surface solar radiation product (edition 2.8) is derived from the CERES sensors on board both NASA EOS satellites, Terra and Aqua. The monthly mean retrieval product spans from early 2000 through present. EOS satellites are sun synchronous with overpasses at 1030 LT (Terra) and 1330 LT (Aqua); thus, 3-hourly geostationary data provide information on the diurnal cycle between $60^{\circ} \mathrm{N}$ and $60^{\circ} \mathrm{S}$, except over snow-covered regions where such data are considered to be of insufficient quality. Full details are available at the CERES website (Table 2) and in the algorithm document (Charlock et al. 1997).

The University of Maryland GOES estimates of $S_{\text {surf }}$ are available for 1996-2010 (Pinker and Laszlo 1992). The product used here has been applied in hydrologic studies (e.g., Jepsen et al. 2012) but is different from the short-term (1996-2001) GOES-8 data used to correct the NLDAS-2 product (Cosgrove et al. 2003).

\section{f. Prior evaluations of solar radiation data}

A number of studies looking at the quality of various solar radiation products have been performed in the past. Hicke (2005) compared NCEP-1 and a product that combined the International Satellite Cloud Climatology Project (ISCCP; Rossow and Schiffer 1999; Zhang et al. 2004) with a radiative transfer model. The GEBA (Gilgen and Ohmura 1999) was used for global comparison for the period 1984-90. It was shown that NCEP-1 substantially overestimated $S_{\text {surf }}$ in all regions other than the Amazon and that the largest relative difference between the products occurred in the high latitudes of the Northern Hemisphere.
Six stations in SURFRAD over the United States were used by Markovic et al. (2009) to compare ERA40, NARR, and ISCCP solar data with the eventual aim of assessing regional climate models. They found that all products had a positive bias, and overall ERA-40 gave a roughly similar mean error to that of ISCCP, though product errors were not consistent at each station.

Shook and Pomeroy (2011) used the MarchSeptember period at eight stations in the prairie and montane regions of Canada for comparison to NARR and NCEP-1 as well as to two empirical methods. Both NARR and NCEP-1 had high biases, and it was suggested that the empirical Annandale et al. (2002) method provided the best result, with NCEP-1 providing the worst.

Kennedy et al. (2011) used 3 years of surface data from the DOE ARM Southern Great Plains (SGP) site in Oklahoma to evaluate MERRA and NARR, finding the common result that both products are biased high (19 and $47 \mathrm{~W} \mathrm{~m}^{-2}$, respectively, for the annual mean), with NARR maintaining a high bias during observed clear-sky periods, suggesting deficiencies in treatment of aerosols and/or water vapor. MERRA's inability to correctly account for cloud cover during precipitation events was demonstrated by Reichle et al. (2011).

Three or more years of data from 1996 to 2001 at 33 FLUXNET sites (Baldocchi et al. 2001) in North America were used by Decker et al. (2012) to evaluate surface meteorology from ERA-40 (Uppala et al. 2005), ERAI, CFSRR, GLDAS-1, MERRA, and NCEP-1. It was suggested that MERRA, ERAI, and NCEP-1 overestimate variability and that for the most part all products overestimated incoming solar radiation. NCEP-1 showed large biases of $25 \mathrm{~W} \mathrm{~m}^{-2}$ or more, while ERAI was noted as having a smaller overall positive bias and standard deviation of errors.

Slater et al. (2013) compared observations taken during NASA's Cold Land Processes Field Experiment (CLPX) in Colorado (Elder et al. 2009) to CFSRR, ERAI, NARR, MERRA, and the GOES product. An average span of $85 \mathrm{~W} \mathrm{~m}^{-2}$ was found among the five products for the month of May at locations containing SNOTEL stations in mountains in the western United States, though this value was reduced to only $40 \mathrm{~W} \mathrm{~m}^{-2}$ when the four most similar products were used. A "best" product could not be clearly identified.

Evaluations have been performed farther afield; for example, Jia et al. (2013) used 3 years (2006-09) of data from 94 stations in China to assess ERAI and the NCEP-DOE AMIP II reanalysis (NCEP-2; Kanamitsu et al.2002), finding positive biases on the order of 25 and $46 \mathrm{~W} \mathrm{~m}^{-2}$, respectively. 
Wang and Zeng (2012) ranked the performance of $S_{\text {surf }}$ from five products (CFSRR, ERAI, GLDAS-1, MERRA, and NCEP-1), comparing up to 3 years of data (2002-04; large portions are missing) at nine highaltitude stations on the Tibetan Plateau. GLDAS-1 was ranked highest in four measurements (correlation, standard deviation of difference from observations, ratio of product to observed standard deviations, and mean bias), with CFSRR and ERAI sharing the next best ranks. The ranks are useful for comparative purposes, though absolute differences in energy cannot be discerned.

ERAI and MERRA were compared to 41 stations in Europe and Africa by Boilley and Wald (2015); both displayed high biases because of underestimation of cloudy conditions, with MERRA faring worse. Zib et al. (2012) compare five reanalyses (20CR, CFSRR, ERAI, MERRA, and NCEP-2) at two high Arctic BSRN stations; they show mean annual biases ranging from $\sim 0$ to over $30 \mathrm{~W} \mathrm{~m}^{-2}$, with ERAI being the best performer, having a bias of less than $3 \mathrm{~W} \mathrm{~m}^{-2}$ at both stations.

\section{Results}

\section{a. Assessment of CSR}

As was shown in Fig. 3a and section 2b(4), the most common values of the CSR when compared to observations were between 0.99 and 1.01. These values follow the expectations that most instruments are correctly measuring $S_{\text {surf }}$. This test alone would suggest that the calculations of CSR and $S_{\text {clear_sky }}$ are robust.

To add further rigor, the CSR of the various largescale products was computed as both a test of the method and as an analysis tool. Ideally, the products would return CSR values of 1.0 in accord with the observations. For each of the products, a CSR was computed for the period 2007-10 for grid boxes containing at least one observation station. The $S_{\text {clear_sky }}$ used here was computed exactly as given in section $2 b(3)$, that is, with observed aerosols and albedo and CFSRR water vapor. Figure 4 gives the unconditional CSR of the products, meaning that the computed CSR value is shown, even if it did not pass the test for ambiguity.

The five most recent reanalyses (20CR, CFSRR, ERAI, JRA-55, and MERRA) all give CSR values within the $0.99-1.01$ range over the majority of the region of interest. Such a result is consistent with observed data and gives further credibility to the robustness of the $S_{\text {clear_sky }}$ computation along with the ability of the CSR algorithm to identify the clear-sky case. At the few places where the CSRs for these reanalyses are outside the range of $0.97-1.03$, such as the far northern coast of
Washington State, the algorithm flagged them as being ambiguous in most of the reanalyses. That is, in this coastal region, using all 4 years of data at once, the algorithm could not confidently say that it had found the clear-sky case; it does not mean that the data are erroneous. NCEP-1 (not shown) and NARR have wellknown issues (section 2f) and returned CSR values well above 1.0, while CSR for the derived products return a range of values. GLDAS- 1 has a low CSR in the Pacific Northwest and mountain regions of the west, while NLDAS-2 performs well on the coasts but poorly inland. Daymet, MsTMIP, and CRU-NCEP consistently return low CSR values, likely because of algorithm error and poor input data choices or bias-correction method (see section 4). GSWP3's low CSR is most likely because of the bias-correction method given that 20CR (its underlying data source) returns a good CSR.

\section{b. Comparison of products and observations}

To facilitate comparison between observations and products, the differing spatial and temporal coverage needs to be reconciled (though no comparison will be perfect). All products were interpolated to the station locations using the closest four land points and a Cressman (1959) scheme in which the radius of influence was chosen to be twice the distance of the maximum gridbox dimension. For each station location, all dates without valid observations were set as missing in the interpolated products. Hence, this "product at station" quantity has the same amount of data as the observations and is used when making comparisons. The two satellite products were subject to slightly different treatment. For CERES, which is a monthly product, prior to interpolation all days within a given month are assigned the monthly value. GOES, unlike the other products, contains some missing values; these were simply left as missing and averages were computed without them, but the conclusions regarding this product are not impacted. The spatial resolution of the product data ranges from $1 \mathrm{~km}$ to $2.5^{\circ}$ and can play a role in details of evaluation; for example, it was noted that when compared to station data, the same product at $0.25^{\circ}$ and $2.5^{\circ}$ resolutions gave increased monthly rootmean-square error (RMSE) from 2.02 to $6.39 \mathrm{~W} \mathrm{~m}^{-2}$ and daily correlation coefficients dropped from 0.996 to 0.969 (Jia et al. 2013). Such a result should be expected, as a better-resolution product (in theory) carries more information. However, the broad conclusions of this work are not altered by such resolution changes.

\section{1) SeAsonal means}

For each month, a mean value of CSR-corrected $S_{\text {surf }}$ was computed if all days contained valid data, and for 


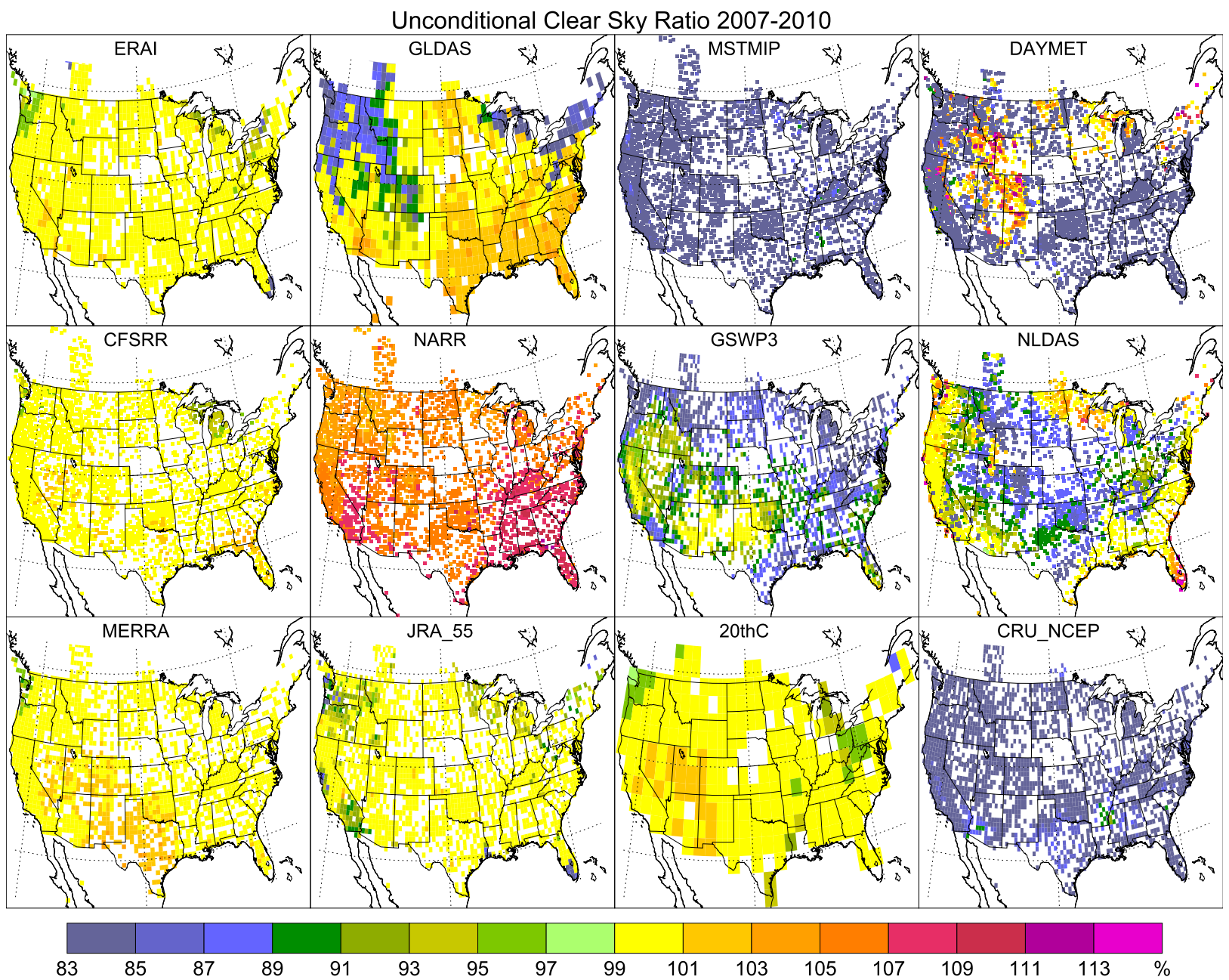

FIG. 4. The CSR [section 2b(4)], expressed as a percentage, for 12 available products calculated over the common years of 2007-10. As would be desirable, the five newer reanalyses (MERRA, CFSRR, ERAI, JRA-55, and 20CR) all return values very close to $100 \%$, while the derivative products give variable CSRs. NCEP-1, GOES, and CERES are omitted.

the period $2000-10$, all valid months for each station were averaged into a monthly climatology, after which seasonal climatologies were made. The amount of data used for the seasonal values varies for each point (though data quantity will be the same for products and observations at a point). For plotting, these values are then interpolated onto the MERRA grid (chosen arbitrarily), only using stations within $100 \mathrm{~km}$ of a grid center (hence vacant areas in the maps).

Figure 5 shows the bias of each product in the seasonal mean for summer months of June-August (JJA) at each grid box, along with the RMSE of these biases. Other seasons are given in the figures in the supplemental material. Thirteen of the fifteen products have a bias RMSE of greater than $18 \mathrm{~W} \mathrm{~m}^{-2}$ (equivalent to greater than $5 \%$ of the observed value). The recent reanalyses (ERAI, MERRA, CFSRR, 20CR, and JRA-55) have a positive bias for much of the CONUS for all seasons, which is generally consistent with prior evaluations (Decker et al. 2012). MERRA deviates with a negative bias in the Gulf of Mexico and lower Atlantic coast region for JJA. These reanalyses produce correct clear-sky values; thus, depiction of clouds within the radiative transfer models are likely responsible for the error. CRU-NCEP and GOES show a distinct negative bias in the west and a positive bias in the east; this pattern is more or less maintained in other seasons. GLDAS- 1 and NLDAS-2 generally have positive biases, but over the mountainous western states, biases tend to be negative or insignificant. Conversely, MsTMIP and Daymet generally have strong negative biases, except over the western mountain areas. NARR (and NCEP-1) has a large positive bias as expected. CERES displays a low error and no distinct spatial pattern and gives the closest 


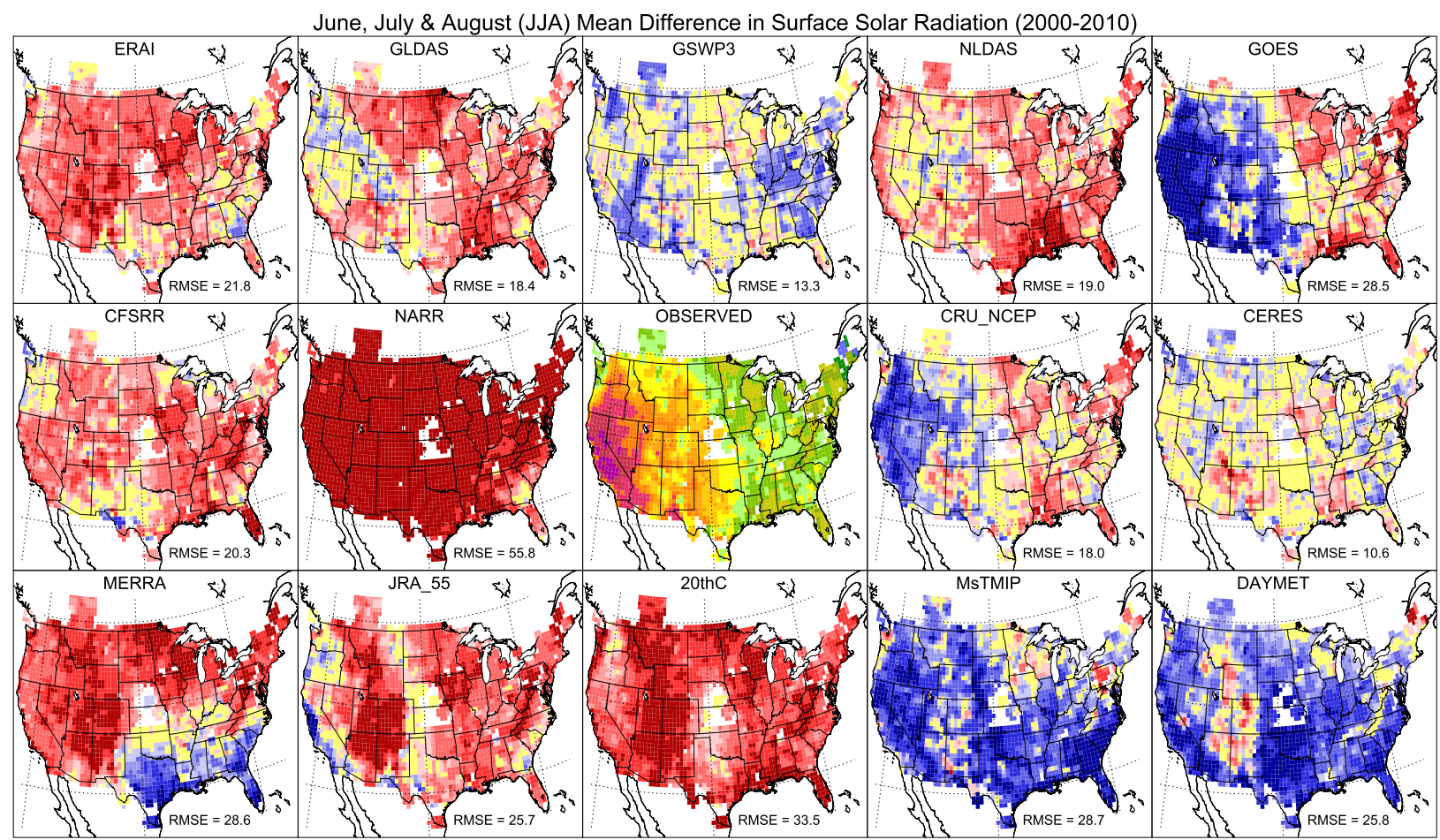

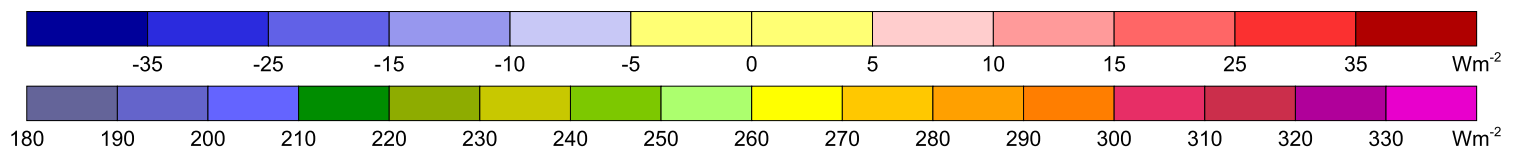

FIG. 5. Mean difference from observed surface solar flux (product minus observed) during JJA for the various products as well as the observed values. NCEP-1, which has a known high bias, is omitted. The difference is calculated using only the same days of data as available in the observations during the common period 2000-10.

rendition to surface observations. GSWP3 has a slightly larger RMSE than CERES, with more negative bias locations. CERES, followed by GSWP3, consistently has the lowest error across all seasons except DecemberFebruary (DJF), when GLDAS-1 has the lowest. Autumn (September-November) errors are slightly lower than winter (DJF), which would not be expected given the seasonal cycle, and may be a result of lower data volumes or possible remaining issues in winter observations.

\section{2) ANNUAL CYCLE}

Figure 6 shows an annual cycle, using monthly means, over the years 2007-09 for six regional zones (denoted by red dots in Fig. 1). At least four stations are used for making the observed quantity and the corresponding product value. Consistent with Fig. 5, some patterns are evident; MsTMIP, GOES, and Daymet are usually the lowest three values while MERRA, NCEP-1, and NARR are the highest, and the ranking of products is fairly consistent (though not always; Fig. 6). The broad annual cycle is captured by most products (e.g., contrast Florida vs California), though the span of annual average radiation over all six regions among the more acceptable products (from CRU-NCEP to MERRA) is $25 \mathrm{~W} \mathrm{~m}^{-2}$, which is more than $12 \%$ of the observed value. Notably, several products over- or underestimate the impact of the particularly cloudy summer months in Florida.

\section{3) Correlation}

To understand variability in $S_{\text {surf }}$, the daily product-atstation data were used to compute the correlation of the clearness index $\left(S_{\text {surf }} / S_{\text {clear_sky }}\right)$, which gives an indication of cloudiness (Fig. 7). Correlation of $S_{\text {surf }}$ alone would result in high values simply because of the annual cycle and thus is less informative. Varying levels of interpolation and different-sized grid boxes are used in creating the product-at-station data; thus, perfect correlation is not expected.

MERRA, CFSRR, ERAI, and GLDAS-1 all correlate between 0.72 and 0.75 against observations, suggesting that cloudiness and synoptic systems are captured to a large degree. In turn, MERRA, CFSRR, ERAI, and JRA-55 all show a high level of correlation 

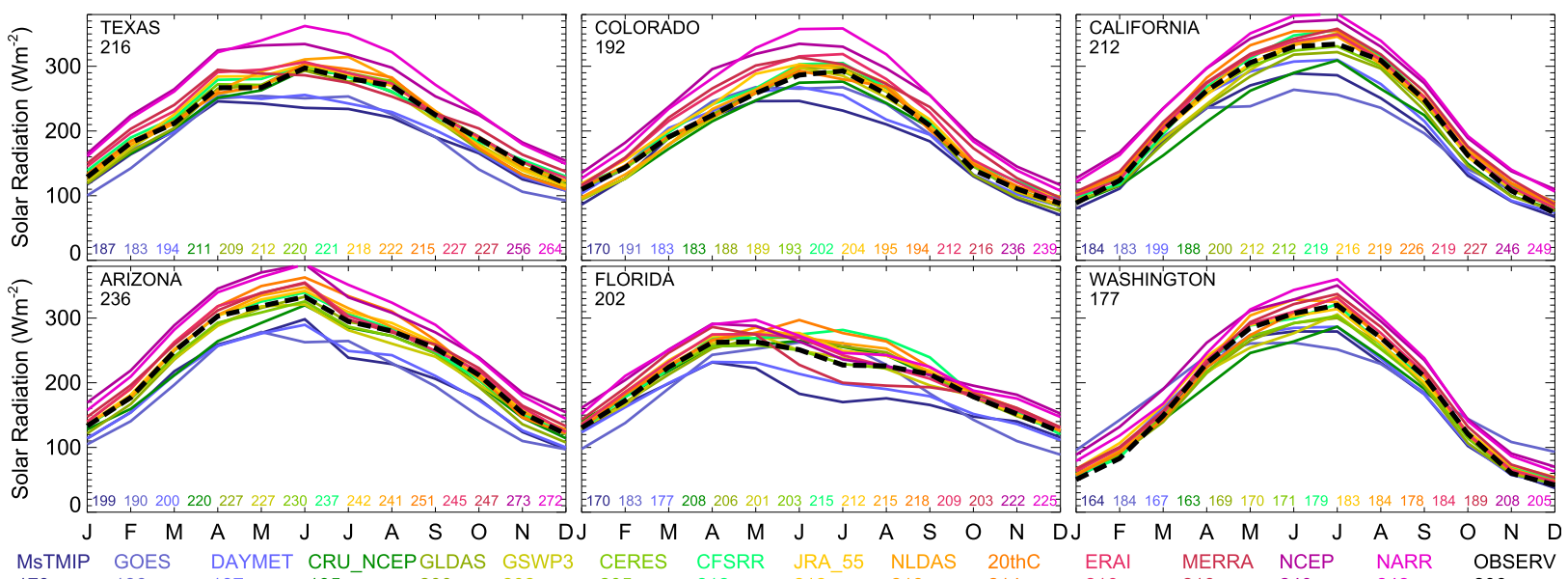
179

FIG. 6. Monthly mean values for six regional clusters of stations for the years 2007-09 for 15 different products and observations. The annual observed mean is given in the upper left corner of each panel and the mean for each product is color coded below each panel. The mean over all six locations is given at the bottom of the figure, along with the color coded key, ranked from lowest to highest. The rankings for each product are fairly consistent.

among each other, perhaps because of assimilation of similar data. Conversely, MsTMIP, Daymet, GSWP3, and 20CR all display lower correlation with observations (and each other). The hereditary properties of products and their respective parents can be seen; NLDAS-2 largely replicates the variability of NARR, CRU-NCEP correlates best with NCEP-1, GSWP3 is closest to 20CR, and MsTMIP is closest to NARR. The GOES product has low correlation compared to all other data at the daily scale, which is consistent with erratic behavior or periods of systematic biases previously seen in western U.S. regions (Jepsen et al. 2012; Slater et al. 2013) as well as the spatial patterns of biases (Fig. 5).

\section{4) DEPARTURE FROM CLEAR-SKY RADIATION}

An alternative view of the data is their departure from

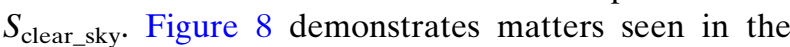
various products over the majority of CONUS locations; Mt. Herman station (southeastern Oklahoma) and the closest product grid box (not interpolated) are shown as an example. MERRA, CFSRR, ERAI, JRA-55, and to a lesser extent $20 \mathrm{CR}$ all show a pronounced envelope of data with a seasonal cycle that reaches $S_{\text {clear_sky, }}$, as in the observations, and confirms CSR results in Fig. 4. The slightly more dispersed results of 20CR might be an artifact of it being an ensemble mean flux, rather than a single deterministic simulation like the other reanalyses. As expected, NCEP-1 and NARR often exceed $S_{\text {clear_sky. }}$ GLDAS-1 shows a dispersed distribution of values, along with an anomaly in 2008-09 that is seen at many other locations for which such analysis was performed. Daymet has excessive amplitude in departure from $S_{\text {clear_sky; }}$; this amplitude is even more pronounced in
MsTMIP (along with an issue in 2010, which appears to be very similar to the NARR value). In keeping with Fig. 4, CRU-NCEP and NLDAS-2 rarely reach $S_{\text {clear_sky, }}$ which may be a function of their bias-correction methods (see section 4b), while GSWP3 also seems to suffer from its bias correction of the 20CR data.

\section{Discussion}

It is likely that many readers will be asking the question, "Which dataset should I use for my model

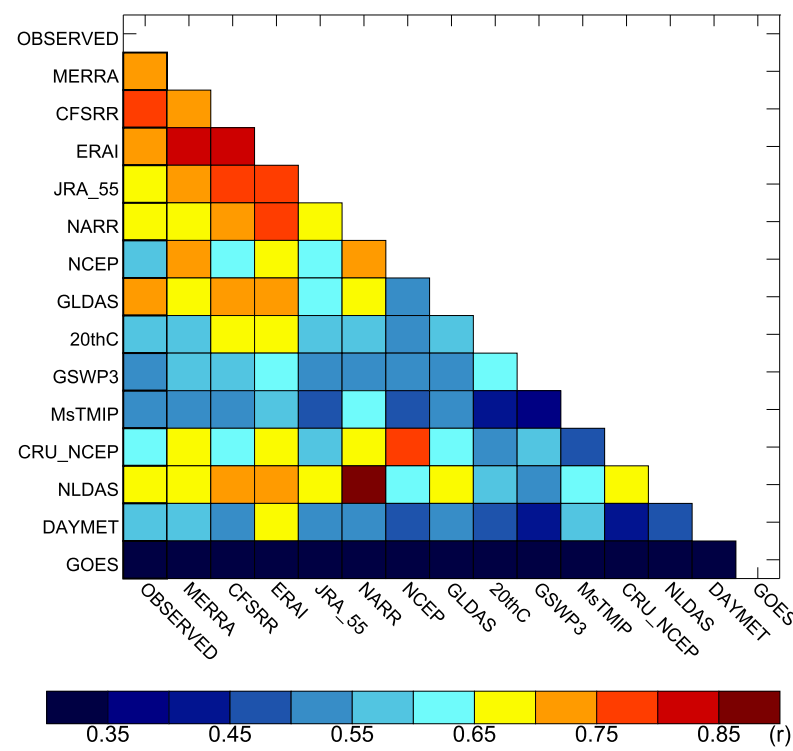

FIG. 7. Correlation of daily clearness index $\left(S_{\text {surf }} / S_{\text {clear_sky }}\right)$ at station locations over the period 2000-10. 


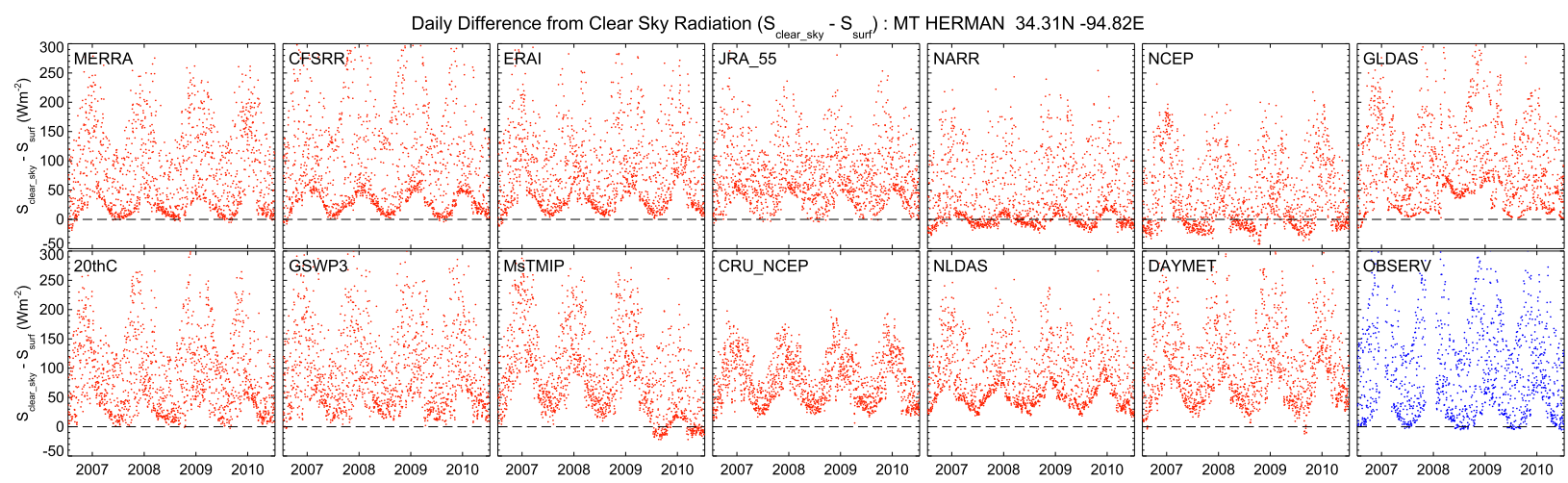

FIG. 8. Plots of the difference between clear-sky radiation and surface radiation (i.e., $S_{\text {clear_sky }}-S_{\text {surf }}$ ) for 13 products and observations at Mt. Herman, Oklahoma. The two satellite products GOES and CERES are omitted.

simulations or analysis?" Unfortunately, none of the products are able to meet the three desirable criteria of low bias, good variability, and correct rendering of $S_{\text {clear_sky. }}$ On the basis of comparison to observations and/or $S_{\text {clear_sky }}$, the NCEP-1, NARR, MsTMIP, CRUNCEP, Daymet, 20CR, and GOES products seem less ideal. The high bias, due to poor rendition of cloud magnitude, in MERRA, CFSRR, ERAI, and JRA-55 detract from their utility, though they capture variability fairly well. GLDAS-1 and NLDAS-2 have midrange performance in each of the three criteria. GSWP3 has good bias performance at the seasonal scale, but other statistical properties are lacking. The monthly CERES product shows the lowest bias, perhaps because of its use of top-of-atmosphere and concurrently retrieved cloud properties (as given in the CERES product processing flowchart; see website, Table 2).

Attributing precise cause to deficiencies in each product is beyond the scope of this study; however, the performance of some products can be linked to specific issues with algorithms and bias-correction methods. These items are explored below. Differences in the various products compared to observations are not spatially constant; therefore, apart from those products that suffer from well-diagnosed deficiencies, it is difficult to extrapolate North American results to other parts of the earth. The region of North America used in this study is one of the most heavily observed in the world with respect to the atmosphere and land surface. A relatively high density of radiosondes should allow for good characterization of $S_{\text {clear_sky }}$ and cloudy synoptic systems. Products may perform better or worse in other locations or different time periods; for example, the CERES product relies on geostationary satellite inputs that are not available outside of $60^{\circ} \mathrm{S}-$ $60^{\circ} \mathrm{N}$ and quality of data products that use satellites for bias correction may not be consistent over time (e.g., pre-2000).

\section{a. Algorithm issues}

Results of the comparison to observed data (Fig. 5) as well as computation of the CSR (Fig. 4) suggest a problem with the Daymet solar radiation algorithm in most locations (other than snow-covered mountainous regions).

To investigate this matter further, the solar radiation code for Daymet, available within the MTCLIM package (http://www.ntsg.umt.edu/project/mtclim) was obtained. MTCLIM 4.3 and MTCLIM, version 4.2 (MTCLIM 4.2), were downloaded and compiled according to instructions, without modification. The daily maximum and minimum temperature and precipitation data, available on a $1 \mathrm{~km} \times 1 \mathrm{~km}$ grid as used for computation of the Daymet product, were used to force both versions (4.3 and 4.2) of the MTCLIM code at the same locations as the surface stations for the years 2007-10. Calculated values from MTCLIM 4.3 are effectively the same as those of the downloaded Daymet solar radiation. The difference between the two versions of the algorithm (4.3 vs 4.2), as an annual mean, can be over $30 \mathrm{~W} \mathrm{~m}^{-2}$ (Fig. 9) and the pattern is similar to the difference between Daymet and observations (in summer; Fig. 5). For regions that might be snow covered, winter values of version 4.3 are typically greater than version 4.2 (e.g., Fig. 10, a northern location). On an annual scale, the snow may explain the continental south-tonorth gradient in differences, as well as noticeable points in the Rocky Mountains (Fig. 9); a snow correction was introduced in version 4.3 (Thornton et al. 2000). For July, version 4.3 is lower than version 4.2 by at least $24 \mathrm{~W} \mathrm{~m}^{-2}$ across the majority of the CONUS (see the figures in the supplemental material).

Bohn et al. (2013) performed an assessment of the MTCLIM algorithms, embedded within the hydrological VIC (http://www.hydro.washington.edu/Lettenmaier/ Models/VIC/), and suggest that acceptable results will be 
Annual: MTCLIM 4.3

Annual: Difference $(4.3-4.2)$

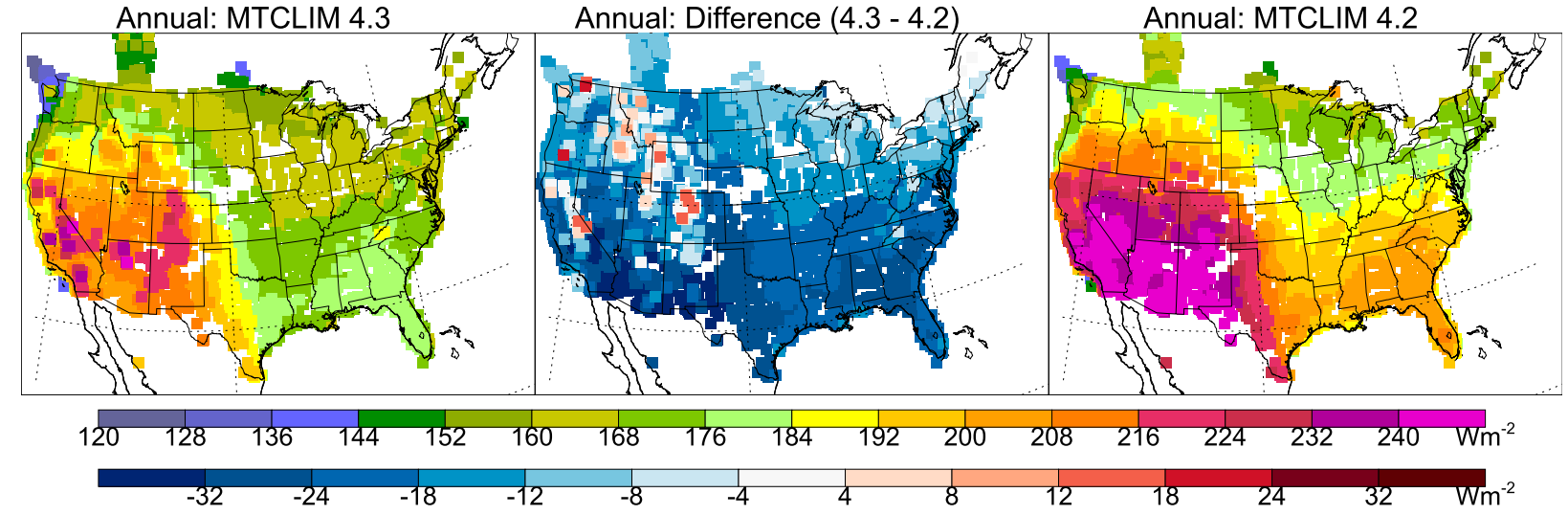

FIG. 9. The mean annual global surface solar radiation (i.e., $S_{\text {surf }}$ ) calculated by MTCLIM (left) 4.3 and (right) 4.2 and (middle) their difference at the same locations as stations. Temperature and precipitation to force the algorithms is taken from the Daymet archive.

given. They show a global estimate of the number of months during which the MTCLIM algorithm has a bias of $10 \%$ or more of local radiation. For North America, they expect that the only places to experience biases of $+10 \%$ for more than 2 months of the year are up in the high Arctic of Canada, the western coastal portion of Arctic Alaska, the Pacific Northwest coast, and the Canadian Rocky Mountains. This conclusion is derived indirectly via regression of bias error against inputs of daily temperature range and an aridity measure (the ratio of daily potential evaporation to annual precipitation) as quality observed $S_{\text {surf }}$ data are usually more difficult to find than temperature and precipitation. Upon consultation with T. Bohn (2015, personal communication), it is noted that this global estimate was made with MTCLIM 4.2, not MTCLIM 4.3 [which perhaps is not clear in Bohn et al. (2013)] and explains why their results do not contain the same errors shown by the Daymet data. VIC-based MTCLIM code has been used in other studies with reasonable results, for example, Mizukami et al. (2014), who further showed that biases in daily temperature range will impact the radiation results.

Results in Figs. 4 and 5 also suggest that problems with MTCLIM 4.3 have propagated to MsTMIP data, which gives the lowest radiation of all products. The use of 3-hourly averaged temperature values when compiling daily maxima and minima for driving the MTCLIM algorithm has perhaps resulted in not correctly resolving the full diurnal temperature range so the algorithm response would likely be muted further (cf. Mizukami et al. 2014). Wei et al. (2014, their Fig. 3), however, show very good performance of the MsTMIP data when compared to an average annual cycle of 23 FLUXNET sites. This result might be explained by partial use of 2010 data that are distinctly different from preceding years (though neither the locations nor time period of comparison are given, so it is hard to say). The figures in the supplemental material of Wei et al. (2014) indicate that MsTMIP $S_{\text {surf }}$ is considerably lower than CRU-NCEP, which is more consistent with results here.

\section{b. Bias-correction methods}

Prior investigations of $S_{\text {surf }}$ data products have noted their biases (see section 2f). A typical method of ameliorating this problem has been to simply multiply $S_{\text {surf }}$ values by the ratio of desired mean $S_{\text {surf }}$ value to the original mean value, often at a monthly or annual scale (Cosgrove et al. 2003; Ngo-Duc et al. 2005). Observed cloud cover combined with regression methods have also been used to determine a bias-correction multiplier (Sheffield et al. 2006; Weedon et al. 2010). Alternatively, regenerating $S_{\text {surf }}$ via algorithms and temporally redistributing data on a proportional basis according to another product (Wei et al. 2014) had variable success (section 4a). However, the use of multipliers can cause problems with reproducing an ideal distribution of $S_{\text {surf }}$ values or CSR (section 3a). The reanalyses that produce good $S_{\text {clear_sky }}$ values tend to be biased high;

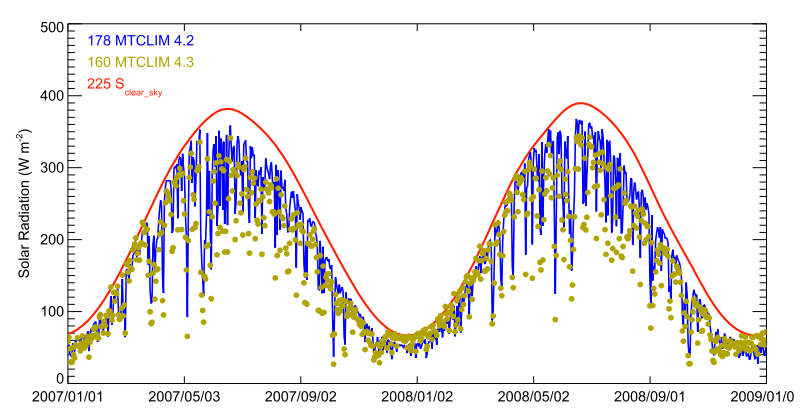

FIG. 10. An example of daily data computed with MTCLIM 4.3 and 4.2, showing that MTCLIM 4.3 gives higher values in winter (presumably in the presence of snow), but considerably lower values in summer. A calculated value of clear-sky radiation serves as a reference. 


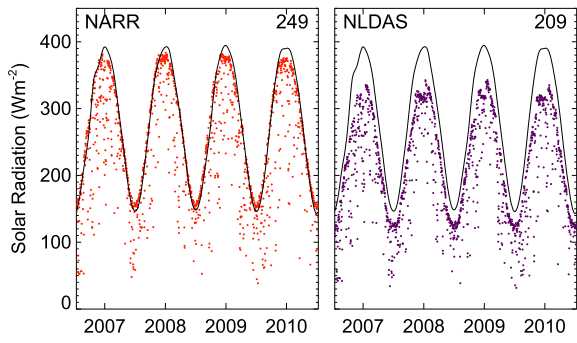

ALTUS $34.58 \mathrm{~N}-99.33 \mathrm{E}$
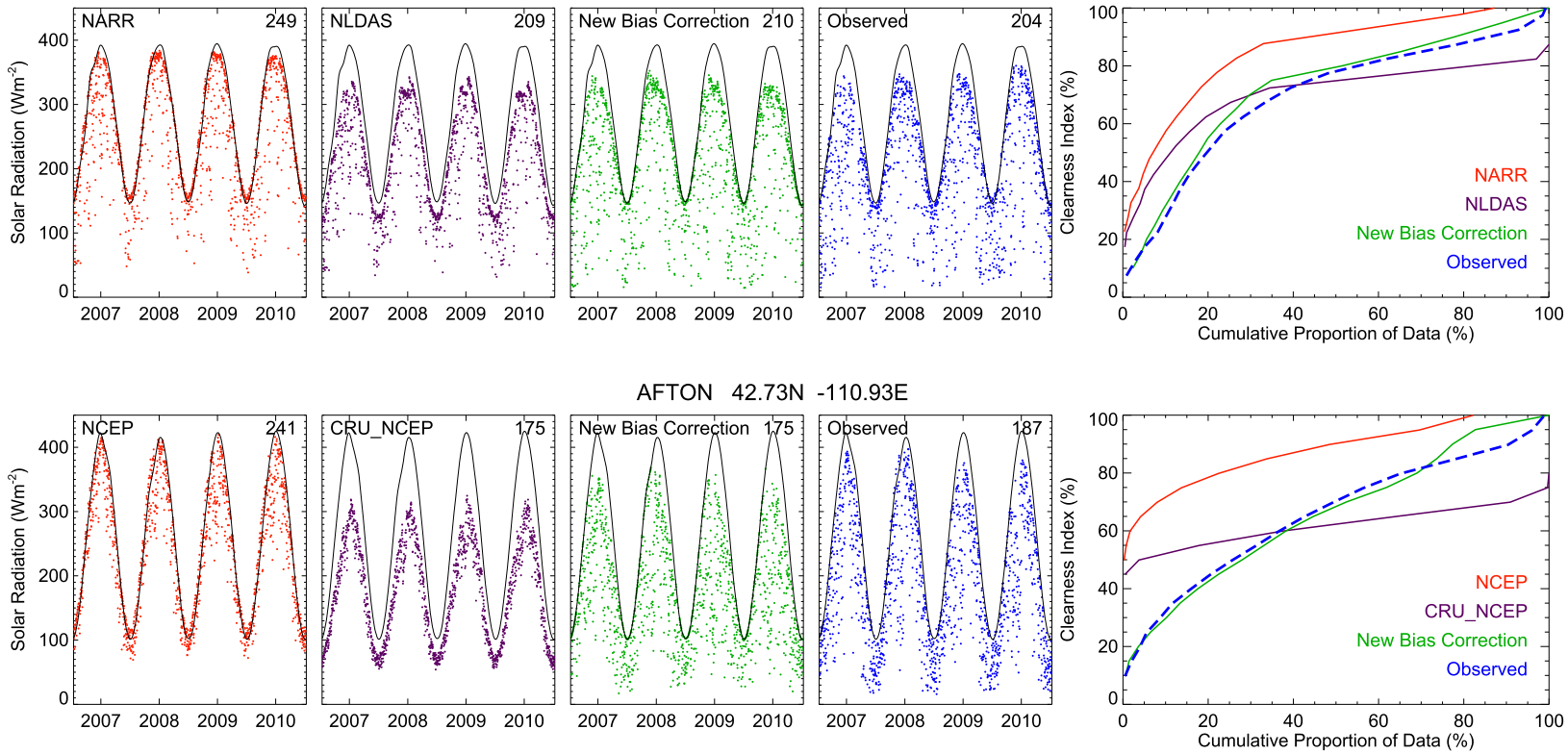

FIG. 11. Example of bias correction. Plots of parent data (NARR and NCEP-1; red), the child product that underwent bias correction (NLDAS-2 and CRU-NCEP; purple), the newly proposed scheme (green), and observations (blue). Clear-sky values (black line) and annual mean values are given for each data stream. The cumulative frequency distribution of the clearness index is given for each case. The relationship between parent and bias-corrected product is evident.

thus, a bias-correction method is needed if such data (which hopefully are consistent with other surface meteorology) are to be used for driving models.

The correct distribution of solar radiation values may be particularly important when considering plant physiology and biogeochemical cycles. The observed relationship between net or gross photosynthesis and incident photosynthetically active radiation (PAR) is nonlinear for many plant species (Kiniry et al. 1999; Rosati and Dejong 2003). Additionally, photosynthesis is more efficient under diffuse radiation conditions $(\mathrm{Gu}$ et al. 2002; Mercado et al. 2009), and most empirical methods of distributing radiation between direct and diffuse beam typically depend nonlinearly on the quantity $S_{\text {surf }}$ (Weiss and Norman 1985; Spitters et al. 1986; Roderick 1999; Oleson et al. 2013). As an example scenario, a pattern of $S_{\text {surf }}$ that does not reach realistic $S_{\text {clear_sky }}$ values may be interpreted as being continually diffuse and lead to simulation of higher growth rates or carbon fixation.

The issues associated with current bias-correction strategies are demonstrated in Fig. 11, which compares bias-corrected products (NLDAS-2 and CRU-NCEP) to their parent data (NARR and NCEP-1) and nearby observations. It can be seen that the standard biascorrection methods may not capture $S_{\text {clear_sky }}$ values or the correct regime of cloudiness (as indicated by the clearness index). Hence, a new method for biascorrecting $S_{\text {surf }}$ is suggested below.
For a given period, which could be a month or a year, first gather the value of the desired mean solar radiation, that is, the final mean bias-corrected value $\bar{S}_{\text {bias corrected. }}$ This value could be obtained from observations or data with a quality longer-term mean but poor temporal resolution. Next, take the time series of the parent data we wish to bias correct $S_{\text {parent }}$ and divide them by their CSR to realign clear-sky values to their correct quantity, giving a series $S_{\mathrm{CSR}}$ :

$$
S_{\mathrm{CSR}}=\frac{S_{\text {parent }}}{\mathrm{CSR}}
$$

The CSR is determined via the method described in section $2 \mathrm{~b}(4)$, and for some products this step will have minimum influence (e.g., the more recent reanalyses; section 3a). However, problems such as excessive or insufficient cloud simulation in the parent data will still cause a bias, so further corrections are needed. Dividing $S_{\text {CSR }}$ by clear-sky values (i.e., $S_{\text {clear_sky }}$ ) gives a series of fractional values that indicate cloudiness:

$$
F_{\text {CSR }}=\frac{S_{\text {CSR }}}{S_{\text {clear_sky }}} \text {. }
$$

These $F_{\mathrm{CSR}}$ values are then adjusted in order to obtain a new set of fractional values $F_{\text {bias_corrected }}$ that will provide us with bias-corrected solar radiation: 


$$
F_{\text {bias_corrected }}=\left(F_{\mathrm{CSR}}\right)^{a} \text {. }
$$

The value of exponent $a$ is found via iteration, with the goal of minimizing the difference in mean values $\Delta \bar{S}$ between the original and bias-corrected data streams over the given period of time (e.g., a month or a year):

$$
\Delta \bar{S}=\bar{S}_{\text {parent }}-\bar{S}_{\text {bias_corrected }},
$$

where

$$
S_{\text {bias_corrected }}=F_{\text {bias_corrected }}\left(S_{\text {clear_sky }}\right)
$$

and limits are imposed on the values of $F_{\text {bias_corrected, }}$

$$
0.10 \leq F_{\text {bias_corrected }} \leq 1.00,
$$

as values should (usually) not exceed the clear-sky value. The proposed method can be applied for hourly as well as daily data and is able to increase or decrease mean values of $S_{\text {surf. }}$.

A remaining limitation of bias corrections discussed here is that if the temporal distribution of cloudy events in the parent data is poor, the final bias-corrected data will still retain vestiges of that problem. However, the correlation of more recent reanalyses with observations [section $3 \mathrm{~b}(3)$ ] suggests that the occurrence of cloudy events tends to be captured (though their impact on $S_{\text {surf }}$ is often incorrect). Reproducing cloud events, regardless of their magnitude, is perhaps aided by the extensive assimilation of atmospheric temperature and humidity data (particularly over the CONUS) into reanalyses.

A demonstration of the new scheme is given in Fig. 11. The only required inputs are a time series of the parent data (in this case NARR and NCEP-1 data), along with the values that represent the bias correction (in this case the annual mean of the child products NLDAS-2 and CRU-NCEP). The new scheme achieves the same level of bias correction as the existing products; for example, mean annual $S_{\text {surf }}$ is reduced from 249 at Altus, Oklahoma, to 209 or $210 \mathrm{~W} \mathrm{~m}^{-2}$ and Afton, Wyoming, shows a reduction in $S_{\text {surf }}$ from 241 to $175 \mathrm{~W} \mathrm{~m}^{-2}$ (Fig. 11), but the distribution of cloudiness is much closer to that seen in station data at the same locations.

\section{Conclusions}

Solar radiation is an extremely important part of the surface energy balance and numerous products have been developed to provide complete spatial and temporal coverage of the CONUS region. There are considerably more observed solar radiation data available than were used in this study. Spatial gaps, such as over
Nebraska, could be filled as additional networks exist or are developing, for example, the National Ecological Observing Network (NEON). A balance between appropriate recognition of data providers relative to data access is desirable; the author therefore wishes to again recognize the entities listed in Tables 1 and 2 and their sponsors. The quantity of data available over the CONUS in the last few years would suggest that an observation-based product of daily $S_{\text {surf }}$ is feasible; a near-real-time hourly data product may even be a possibility.

There is potential to assimilate $S_{\text {surf }}$ values directly into reanalysis systems, for example, to update aerosol loading or precipitable water content and give better cloud fraction diagnoses, but this would not be a trivial exercise. A more tractable alternative could be to reprocess existing operational analysis and reanalysis surface meteorology products beyond simple bias correction with assimilation of observed $S_{\text {surf }}$ and other quantities observed at stations (temperature, humidity, etc.). Along these lines, compilation of the individual surface meteorology variables used for driving hydrologic, land, and ecologic models would preferably not be done in isolation. Ideally, there would be an observationally based internal consistency between all variables at the time step of the data series; for example, temperature, humidity, radiation, and precipitation would be all consistent with each other on an hourly basis.

Excluding direct use of station observations, a best effort for the CONUS may be to take CFSRR or ERAI and bias correct them to the monthly CERES values using a method similar to that given in section $4 \mathrm{~b}$ so as to mimic appropriate cloud conditions and $S_{\text {clear_sky }}$ values. Solar radiation products used for model assessment and/or development should achieve greater fidelity to reality than simply having a low bias on monthly mean values. This may be particularly important for the new generation of land models that simulate mass, energy exchange along with plant physiological processes, and biogeochemical fluxes and/or dynamic vegetation (whether implicit or explicit).

In summary, this study brought together extensive observations of daily solar radiation and applied a QC procedure that is designed to both screen for bad data and rescue data that would otherwise be considered erroneous. Fifteen different solar radiation products were compared to these observations, as well as to each other, using a variety of metrics and methods. No product replicated all aspects of the station-based data and there is room for improvement, though some products can be identified as better than others. Underlying issues with a commonly used algorithm (MTCLIM 4.3) were demonstrated, suggesting that the current version of 
algorithm and data product wants revision. Last, a new method for bias-correcting $S_{\text {surf }}$ data was proposed, and it was shown to reproduce the distribution of cloudiness better than current methods. The conclusions regarding the various products are broad in nature and give a generalization of the study region as a whole; however, it should be noted that particular locations or localized regions may see different levels of performance by some products.

Acknowledgments. Support for this work was provided by the U.S. Army Corps of Engineers and NOAA (Grant NA11OAR4310142). The sources of observational data are too numerous to list in this section but are given in Table 1 of the text, and all observation providers (along with their sponsors) are gratefully acknowledged for maintaining stations and posting data to the web. A condition of use for large portions of these data is that they not be distributed by third parties. Product data and websites are similarly listed in Table 2 of the text and acknowledgement is given to all data sources. The Research Data Archive (RDA) at NCAR was used to obtain some reanalysis data. Thanks to Laura Hinkelman, Paquita Zuidema, and Martyn Clark for discussion. An anonymous reviewer and Ted Bohn are thanked for their very useful comments on this work.

\section{REFERENCES}

Anderson, E. A., 1973: National Weather Service River Forecast System-Snow accumulation and ablation model. NOAA Tech. Memo. NWS HYDRO-17, 87 pp. [Available online at ftp:// ftp.wcc.nrcs.usda.gov/wntsc/H\&H/snow/AndersonHYDRO17. pdf.]

- 2006: Snow accumulation and ablation model-SNOW-17. User's manual, NWS, 61 pp. [Available online at http://www. nws.noaa.gov/oh/hrl/nwsrfs/users_manual/part2/_pdf/22snow17. pdf.]

Annandale, J., N. Jovanovic, N. Benade, and R. Allen, 2002: Software for missing data error analysis of Penman-Monteith reference evapotranspiration. Irrig. Sci., 21, 57-67, doi:10.1007/ s002710100047.

Baldocchi, D., and Coauthors, 2001: FLUXNET: A new tool to study the temporal and spatial variability of ecosystemscale carbon dioxide, water vapor, and energy flux densities. Bull. Amer. Meteor. Soc., 82, 2415-2434, doi:10.1175/ 1520-0477(2001)082<2415:FANTTS > 2.3.CO;2.

Berg, A. A., J. S. Famiglietti, J. P. Walker, and P. R. Houser, 2003: Impact of bias correction to reanalysis products on simulations of North American soil moisture and hydrological fluxes. J. Geophys. Res., 108, 4490, doi:10.1029/2002JD003334.

Berliand, T., 1960: Method of climatological calculation of global radiation. Meteor. Gidrol., 6, 9-12.

Bird, R., and R. Hulstrom, 1981: A simplified clear sky model for direct and diffuse insolation on horizontal surfaces. SERI Tech. Rep. 642-761, Solar Energy Research Institute, Golden, CO, 38 pp. [Available online at http://rredc.nrel.gov/solar/ pubs/pdfs/tr-642-761.pdf.]
Bohn, T. J., B. Livneh, J. W. Oyler, S. W. Running, B. Nijssen, and D. P. Lettenmaier, 2013: Global evaluation of MTCLIM and related algorithms for forcing of ecological and hydrological models. Agric. For. Meteor., 176, 38-49, doi:10.1016/ j.agrformet.2013.03.003.

Boilley, A., and L. Wald, 2015: Comparison between meteorological re-analyses from ERA-Interim and MERRA and measurements of daily solar irradiation at surface. Renew. Energy, 75, 135-143, doi:10.1016/j.renene.2014.09.042.

Charlock, T., F. Rose, D. Rutan, T. Alberta, L. Coleman, G. Smith, M. Smith, and T. Bess, 1997: Clouds and the Earth's Radiant Energy System (CERES) algorithm theoretical basis document: Compute surface and atmospheric fluxes (subsystem 5.0). NASA Reference Publ., 84 pp. [Available online at http://ceres.larc. nasa.gov/documents/ATBD/pdf/r2_2/ceres-atbd2.2-s5.0.pdf.]

Compo, G. P., and Coauthors, 2011: The Twentieth Century Reanalysis Project. Quart. J. Roy. Meteor. Soc., 137, 1-28, doi:10.1002/qj.776.

Cosgrove, B. A., and Coauthors, 2003: Real-time and retrospective forcing in the North American Land Data Assimilation System (NLDAS) project. J. Geophys. Res., 108, 8842, doi:10.1029/ 2002JD003118.

Cressman, G., 1959: An operational objective analysis scheme. Mon. Wea. Rev., 87, 367-374, doi:10.1175/1520-0493(1959)087<0367: AOOAS $>2.0 . C O ; 2$.

Cronin, M. F., and M. J. McPhaden, 1997: The upper ocean heat balance in the western equatorial Pacific warm pool during September-December 1992. J. Geophys. Res., 102, 8533-8553, doi:10.1029/97JC00020.

Darnell, W. L., W. F. Staylor, S. K. Gupta, and F. M. Denn, 1988: Estimation of surface insolation using sun-synchronous satellite data. J. Climate, 1, 820-835, doi:10.1175/1520-0442(1988)001<0820: EOSIUS $>2.0 . \mathrm{CO} ; 2$.

Decker, M., M. A. Brunke, Z. Wang, K. Sakaguchi, X. Zeng, and M. G. Bosilovich, 2012: Evaluation of the reanalysis products from GSFC, NCEP, and ECMWF using flux tower observations. J. Climate, 25, 1916-1944, doi:10.1175/JCLI-D-11-00004.1.

Dee, D. P., and Coauthors, 2011: The ERA-Interim reanalysis: Configuration and performance of the data assimilation system. Quart. J. Roy. Meteor. Soc., 137, 553-597, doi:10.1002/qj.828.

Ebita, A., and Coauthors, 2011: The Japanese 55-year Reanalysis "JRA-55": An interim report. SOLA, 7, 149-152, doi:10.2151/ sola.2011-038.

Elder, K., D. Cline, G. E. Liston, and R. Armstrong, 2009: NASA Cold Land Processes Experiment (CLPX 2002/03): Field measurements of snowpack properties and soil moisture. J. Hydrometeor., 10, 320-329, doi:10.1175/2008JHM877.1.

Foltz, G. R., A. T. Evan, H. P. Freitag, S. Brown, and M. J. McPhaden, 2013: Dust accumulation biases in PIRATA shortwave radiation records. J. Atmos. Oceanic Technol., 30, 1414-1432, doi:10.1175/JTECH-D-12-00169.1.

Gilgen, H., and A. Ohmura, 1999: The Global Energy Balance Archive. Bull. Amer. Meteor. Soc., 80, 831-850, doi:10.1175 1520-0477(1999)080<0831:TGEBA > 2.0.CO;2.

Gu, L. H., D. Baldocchi, S. B. Verma, T. A. Black, T. Vesala, E. M. Falge, and P. R. Dowty, 2002: Advantages of diffuse radiation for terrestrial ecosystem productivity. J. Geophys. Res., 107, 4050, doi:10.1029/2001JD001242.

Gueymard, C. A., and D. R. Myers, 2009: Evaluation of conventional and high-performance routine solar radiation measurements for improved solar resource, climatological trends, and radiative modeling. Sol. Energy, 83, 171-185, doi:10.1016/ j.solener.2008.07.015. 
Gupta, S. K., N. A. Ritchey, A. C. Wilber, C. H. Whitlock, G. G. Gibson, and P. W. Stackhouse, 1999: A climatology of surface radiation budget derived from satellite data. J. Climate, 12, 2691-2710, doi:10.1175/1520-0442(1999)012<2691:ACOSRB > 2.0.CO;2.

Hicke, J. A., 2005: NCEP and GISS solar radiation data sets available for ecosystem modeling: Description, differences, and impacts on net primary production. Global Biogeochem. Cycles, 19, GB2006, doi:10.1029/2004GB002391.

Huntzinger, D. N., and Coauthors, 2013: The North American Carbon Program Multi-Scale Synthesis and Terrestrial Model Intercomparison Project-Part 1: Overview and experimental design. Geosci. Model Dev., 6, 2121-2133, doi:10.5194/ gmd-6-2121-2013.

Jepsen, S. M., N. P. Molotch, M. W. Williams, K. E. Rittger, and J. O. Sickman, 2012: Interannual variability of snowmelt in the Sierra Nevada and Rocky Mountains, United States: Examples from two alpine watersheds. Water Resour. Res., 48 , W02529, doi:10.1029/2011WR011006.

Jia, B., Z. Xie, A. Dai, C. Shi, and F. Chen, 2013: Evaluation of satellite and reanalysis products of downward surface solar radiation over East Asia: Spatial and seasonal variations. J. Geophys. Res. Atmos., 118, 3431-3446, doi:10.1002/jgrd.50353.

Journee, M., and C. Bertrand, 2011: Quality control of solar radiation data within the RMIB solar measurements network. Sol. Energy, 85, 72-86, doi:10.1016/j.solener.2010.10.021.

Kalnay, E., and Coauthors, 1996: The NCEP/NCAR 40-Year Reanalysis Project. Bull. Amer. Meteor. Soc., 77, 437-471, doi:10.1175/1520-0477(1996)077<0437:TNYRP>2.0.CO;2.

Kanamitsu, M., W. Ebisuzaki, J. Woollen, S. K. Yang, J. J. Hnilo, M. Fiorino, and G. L. Potter, 2002: NCEP-DOE AMIP-II Reanalysis (R-2). Bull. Amer. Meteor. Soc., 83, 1631-1643, doi:10.1175/BAMS-83-11-1631.

Kato, S., N. G. Loeb, F. G. Rose, D. R. Doelling, D. A. Rutan, T. E. Caldwell, L. Yu, and R. A. Weller, 2013: Surface irradiances consistent with CERES-derived top-of-atmosphere shortwave and longwave irradiances. J. Climate, 26, 2719-2740, doi:10.1175/ JCLI-D-12-00436.1.

Kennedy, A. D., X. Dong, B. Xi, S. Xie, Y. Zhang, and J. Chen, 2011: A comparison of MERRA and NARR reanalyses with the DOE ARM SGP data. J. Climate, 24, 4541-4557, doi:10.1175/2011JCLI3978.1.

Kiniry, J. R., C. R. Tischler, and G. A. Van Esbroeck, 1999: Radiation use efficiency and leaf $\mathrm{CO}_{2}$ exchange for diverse $\mathrm{C}_{4}$ grasses. Biomass Bioenergy, 17, 95-112, doi:10.1016/S0961-9534(99)00036-7.

Kobayashi, S., and Coauthors, 2015: The JRA-55 Reanalysis: General specifications and basic characteristics. J. Meteor. Soc. Japan, 93, 5-48, doi:10.2151/jmsj.2015-001.

Livneh, B., E. A. Rosenberg, C. Lin, B. Nijssen, V. Mishra, K. M. Andreadis, E. P. Maurer, and D. P. Lettenmaier, 2013: A longterm hydrologically based dataset of land surface fluxes and states for the conterminous United States: Update and extensions. J. Climate, 26, 9384-9392, doi:10.1175/JCLI-D-12-00508.1.

Markovic, M., C. G. Jones, K. Winger, and D. Paquin, 2009: The surface radiation budget over North America: Gridded data assessment and evaluation of regional climate models. Int. J. Climatol., 29, 2226-2240, doi:10.1002/joc.1860.

Mercado, L. M., N. Bellouin, S. Sitch, O. Boucher, C. Huntingford, M. Wild, and P. M. Cox, 2009: Impact of changes in diffuse radiation on the global land carbon sink. Nature, 458, 10141017, doi:10.1038/nature07949.

Mesinger, F., and Coauthors, 2006: North American Regional Reanalysis. Bull. Amer. Meteor. Soc., 87, 343-360, doi:10.1175/ BAMS-87-3-343.
Mizukami, N., M. P. Clark, A. G. Slater, L. D. Brekke, M. M. Elsner, J. R. Arnold, and S. Gangopadhyay, 2014: Hydrologic implications of different large-scale meteorological model forcing datasets in mountainous regions. J. Hydrometeor., 15, 474-488, doi:10.1175/JHM-D-13-036.1.

Monteith, J., 1972: Solar radiation and productivity in tropical ecosystems. J. Appl. Ecol., 9, 747-766, doi:10.2307/2401901.

Ngo-Duc, T., J. Polcher, and K. Laval, 2005: A 53-year forcing data set for land surface models. J. Geophys. Res., 110, D06116, doi:10.1029/2004JD005434.

Oleson, K. W., and Coauthors, 2013: Technical description of version 4.5 of the Community Land Model (CLM). NCAR Tech. Note NCAR/TN-503+STR, 420 pp., doi:10.5065/ D6RR1W7M.

Piao, S., and Coauthors, 2013: Evaluation of terrestrial carbon cycle models for their response to climate variability and to $\mathrm{CO}_{2}$ trends. Global Change Biol., 19, 2117-2132, doi:10.1111/ gcb.12187.

Pinker, R., and I. Laszlo, 1992: Modeling surface solar irradiance for satellite applications on a global scale. J. Appl. Meteor., 31, 194-211, doi:10.1175/1520-0450(1992)031<0194: MSSIFS $>2.0 . \mathrm{CO} ; 2$.

Reichelstein, S., and M. Yorston, 2013: The prospects for cost competitive solar PV power. Energy Policy, 55, 117-127, doi:10.1016/j.enpol.2012.11.003.

Reichle, R. H., R. D. Koster, G. J. M. De Lannoy, B. A. Forman, Q. Liu, S. P. P. Mahanama, and A. Toure, 2011: Assessment and enhancement of MERRA land surface hydrology estimates. J. Climate, 24, 6322-6338, doi:10.1175/JCLI-D-10-05033.1.

Rienecker, M. M., and Coauthors, 2011: MERRA: NASA's Modern-Era Retrospective Analysis for Research and Applications. J. Climate, 24, 3624-3648, doi:10.1175/JCLI-D-11-00015.1.

Rodell, M., and Coauthors, 2004: The Global Land Data Assimilation System. Bull. Amer. Meteor. Soc., 85, 381-394, doi:10.1175/ BAMS-85-3-381.

Roderick, M. L., 1999: Estimating the diffuse component from daily and monthly measurements of global radiation. Agric. For. Meteor., 95, 169-185, doi:10.1016/S0168-1923(99)00028-3.

Rosati, A., and T. M. Dejong, 2003: Estimating photosynthetic radiation use efficiency using incident light and photosynthesis of individual leaves. Ann. Bot., 91, 869-877, doi:10.1093/aob/ mcg094.

Rossow, W. B., and R. A. Schiffer, 1999: Advances in understanding clouds from ISCCP. Bull. Amer. Meteor. Soc., 80, 2261-2287, doi:10.1175/1520-0477(1999)080<2261:AIUCFI >2.0.CO;2.

Saha, S., and Coauthors, 2010: The NCEP Climate Forecast System Reanalysis. Bull. Amer. Meteor. Soc., 91, 1015-1057, doi:10.1175/ 2010BAMS3001.1.

— , and Coauthors, 2014: The NCEP Climate Forecast System version 2. J. Climate, 27, 2185-2208, doi:10.1175/JCLI-D-12-00823.1.

Schaaf, C. B., and Coauthors, 2002: First operational BRDF, albedo nadir reflectance products from MODIS. Remote Sens. Environ., 83, 135-148, doi:10.1016/S0034-4257(02)00091-3.

Shapiro, R., 1987: A simple model for the calculation of the flux of direct and diffuse solar radiation through the atmosphere. AFGL-TR-87-0200, Air Force Geophysics Laboratory, Hanscom AFB, 40 pp.

Sheffield, J., G. Goteti, and E. F. Wood, 2006: Development of a 50-year high-resolution global dataset of meteorological forcings for land surface modeling. J. Climate, 19, 3088-3111, doi:10.1175/JCLI3790.1.

Shi, G.-Y., T. Hayasaka, A. Ohmura, Z.-H. Chen, B. Wang, J.-Q. Zhao, H.-Z. Che, and L. Xu, 2008: Data quality assessment 
and the long-term trend of ground solar radiation in China. J. Appl. Meteor. Climatol., 47, 1006-1016, doi:10.1175/ 2007JAMC1493.1.

Shook, K., and J. Pomeroy, 2011: Synthesis of incoming shortwave radiation for hydrological simulation. Hydrol. Res., 42, 433446, doi:10.2166/nh.2011.074

Slater, A. G., A. P. Barrett, M. P. Clark, J. D. Lundquist, and M. S. Raleigh, 2013: Uncertainties in seasonal snow reconstruction: Relative impacts of model forcing and image availability. $A d v$. Water Resour., 55, 165-177, doi:10.1016/j.advwatres.2012.07.006.

Spitters, C., H. Toussaint, and J. Goudraain, 1986: Separating the diffuse and direct component of global radiation and its implications for modeling canopy photosynthesis. 1. Components of incoming radiation. Agric. For. Meteor., 38, 217-229, doi:10.1016/0168-1923(86)90060-2.

Stoffel, T. L., I. Reda, D. R. Myers, D. Renne, S. Wilcox, and J. Treadwell, 2000: Current issues in terrestrial solar radiation instrumentation for energy, climate, and space applications. Metrologia, 37, 399-402, doi:10.1088/0026-1394/37/5/11.

Thornton, P., and S. Running, 1999: An improved algorithm for estimating incident daily solar radiation from measurements of temperature, humidity, and precipitation. Agric. For. Meteor., 93, 211-228, doi:10.1016/S0168-1923(98)00126-9.

, H. Hasenauer, and M. White, 2000: Simultaneous estimation of daily solar radiation and humidity from observed temperature and precipitation: An application over complex terrain in Austria. Agric. For. Meteor., 104, 255-271, doi:10.1016/ S0168-1923(00)00170-2.

Uppala, S., and Coauthors, 2005: The ERA-40 re-analysis. Quart. J. Roy. Meteor. Soc., 131, 2961-3012, doi:10.1256/qj.04.176.

Wang, A., and X. Zeng, 2012: Evaluation of multireanalysis products with in situ observations over the Tibetan Plateau. J. Geophys. Res., 117, D05102, doi:10.1029/2011JD016553.

Weedon, G. P., S. Gomes, P. Viterbo, H. Oesterle, J. C. Adam, N. Bellouin, O. Boucher, and M. Best, 2010: The WATCH forcing data 1958-2001: A meteorological forcing dataset for land surface- and hydrological-models. Tech. Rep. 22, WATCH, $41 \mathrm{pp}$.

Wei, Y., and Coauthors, 2014: The North American Carbon Program Multi-scale Synthesis and Terrestrial Model Intercomparison Project-Part 2: Environmental driver data. Geosci. Model Dev., 7, 2875-2893, doi:10.5194/gmd-7-2875-2014.

Weiss, A., and J. Norman, 1985: Partitioning solar radiation into direct and diffuse, visible and near-infrared components. Agric. For. Meteor., 34, 205-213, doi:10.1016/ 0168-1923(85)90020-6.

Wild, M., and Coauthors, 2014: The energy balance over land and oceans: An assessment based on direct observations and CMIP5 climate models. Climate Dyn., 44, 3393-3429, doi:10.1007/s00382-014-2430-z.

Yoshimura, K., and M. Kanamitsu, 2013: Incremental correction for the dynamical downscaling of ensemble mean atmospheric fields. Mon. Wea. Rev., 141, 3087-3101, doi:10.1175/ MWR-D-12-00271.1.

Younes, S., R. Claywell, and T. Muneer, 2005: Quality control of solar radiation data: Present status and proposed new approaches. Energy, 30, 1533-1549, doi:10.1016/j.energy.2004.04.031.

Zhang, Y. C., W. B. Rossow, A. A. Lacis, V. Oinas, and M. I. Mishchenko, 2004: Calculation of radiative fluxes from the surface to top of atmosphere based on ISCCP and other global data sets: Refinements of the radiative transfer model and the input data. J. Geophys. Res., 109, D19105, doi:10.1029/ 2003JD004457.

Zhao, M., S. W. Running, and R. R. Nemani, 2006: Sensitivity of Moderate Resolution Imaging Spectroradiometer (MODIS) terrestrial primary production to the accuracy of meteorological reanalyses. J. Geophys. Res., 111, G01002, doi:10.1029/ 2004JG000004.

Zib, B. J., X. Dong, B. Xi, and A. Kennedy, 2012: Evaluation and intercomparison of cloud fraction and radiative fluxes in recent reanalyses over the Arctic using BSRN surface observations. J. Climate, 25, 2291-2305, doi:10.1175/JCLI-D-11-00147.1. 